OAK RIDGE

NATIONAL LABORATORY

MANAGED BY UT-BATTELLE

FOR THE DEPARTMENT OF ENERGY

\title{
Intermittent Ventilation Energy Demands and Indoor Air Quality in Mixed-Humid Climates
}

\section{March 2014}

\section{Prepared by}

Diana E. Hun

Mark C. Jackson

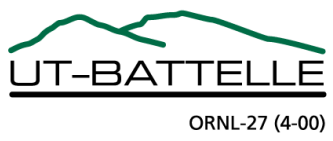




\section{DOCUMENT AVAILABILITY}

Reports produced after January 1, 1996, are generally available free via the U.S. Department of Energy (DOE) Information Bridge.

Web site http://www.osti.gov/bridge

Reports produced before January 1, 1996, may be purchased by members of the public from the following source.

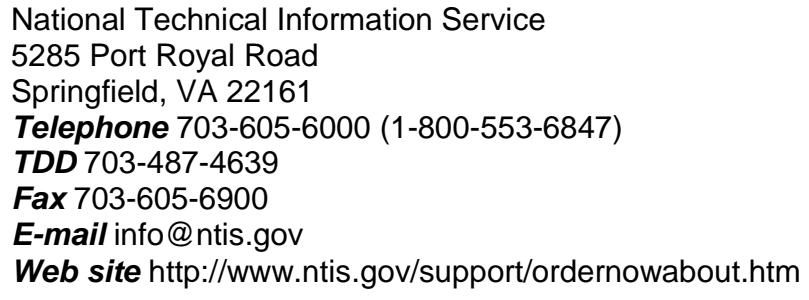

Reports are available to DOE employees, DOE contractors, Energy Technology Data Exchange (ETDE) representatives, and International Nuclear Information System (INIS) representatives from the following source.

Office of Scientific and Technical Information

P.O. Box 62

Oak Ridge, TN 37831

Telephone 865-576-8401

Fax 865-576-5728

E-mail reports@osti.gov

Web site http://www.osti.gov/contact.html

This report was prepared as an account of work sponsored by an agency of the United States Government. Neither the United States Government nor any agency thereof, nor any of their employees, makes any warranty, express or implied, or assumes any legal liability or responsibility for the accuracy, completeness, or usefulness of any information, apparatus, product, or process disclosed, or represents that its use would not infringe privately owned rights. Reference herein to any specific commercial product, process, or service by trade name, trademark, manufacturer, or otherwise, does not necessarily constitute or imply its endorsement, recommendation, or favoring by the United States Government or any agency thereof. The views and opinions of authors expressed herein do not necessarily state or reflect those of the United States Government or any agency thereof. 


\title{
Intermittent Ventilation Energy Demands and Indoor Air Quality in Mixed-Humid Climates
}

\author{
Diana E. Hun \\ Mark C. Jackson
}

Date Published: March 2014

\author{
Prepared by \\ OAK RIDGE NATIONAL LABORATORY \\ Oak Ridge, Tennessee 37831-6283 \\ managed by \\ UT-BATTELLE, LLC \\ for the \\ U.S. DEPARTMENT OF ENERGY \\ under contract DE-AC05-00OR22725
}




\section{Content}

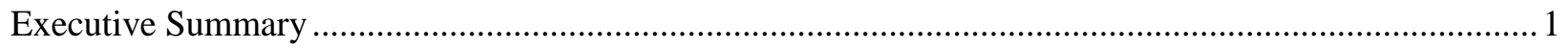

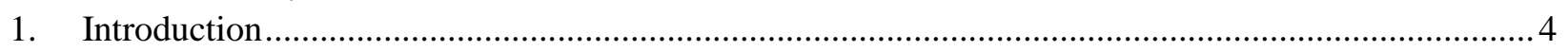

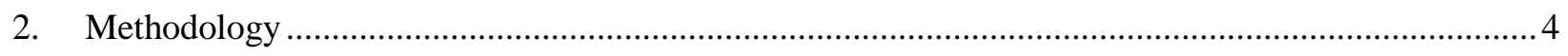

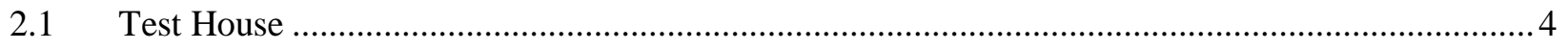

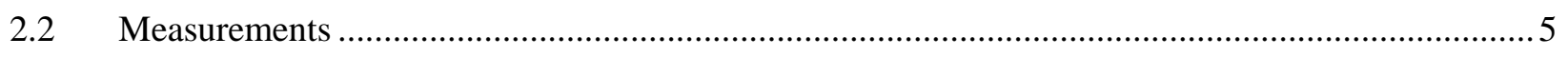

2.2.1 Volatile Organic Compounds and Formaldehyde ..............................................................

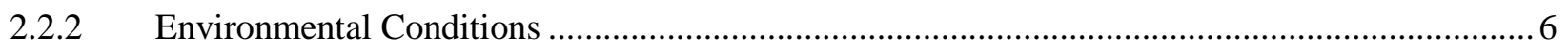

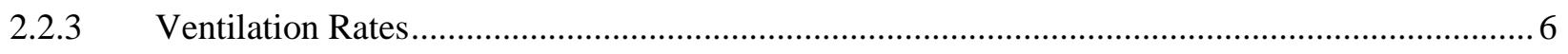

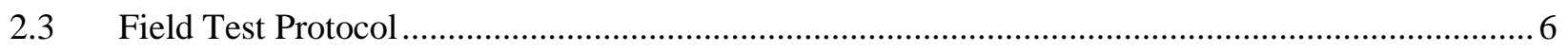

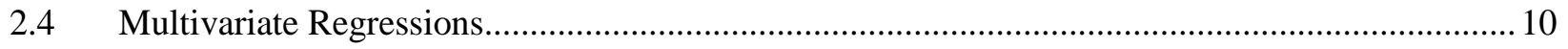

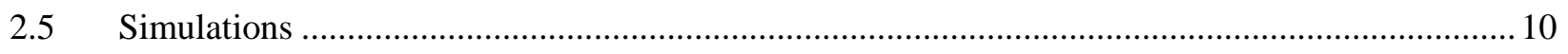

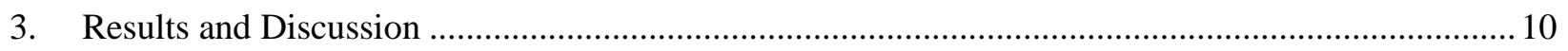

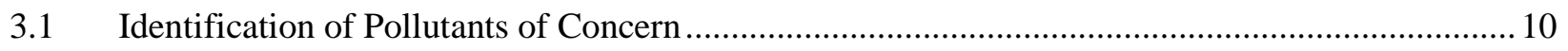

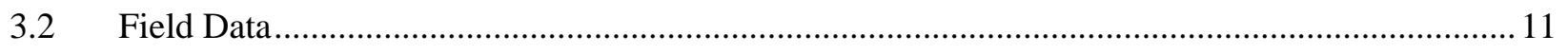

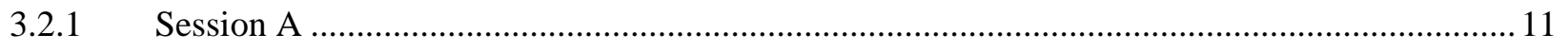

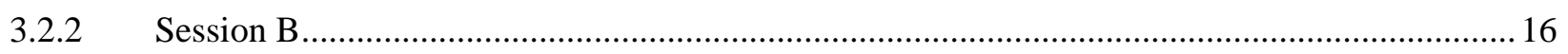

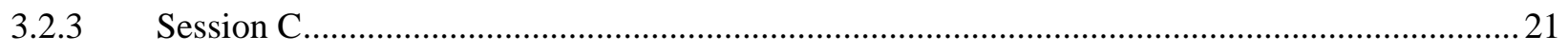

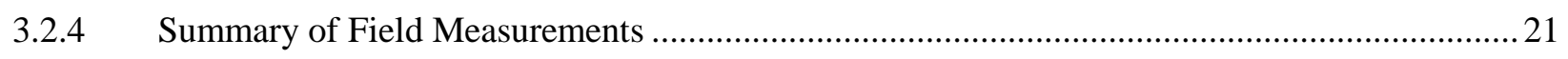

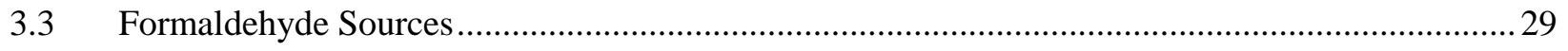

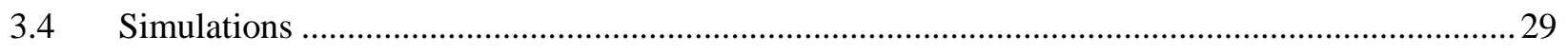

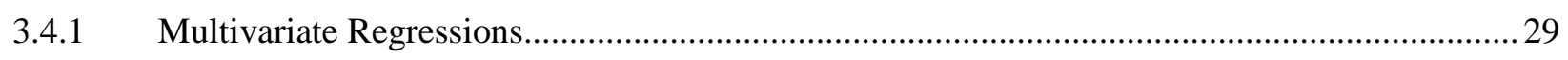

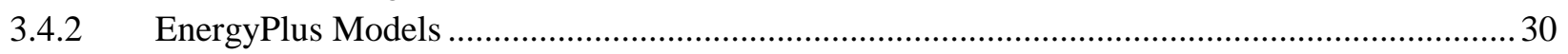

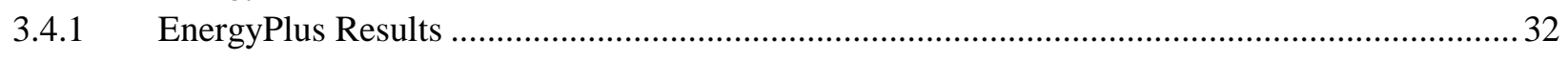

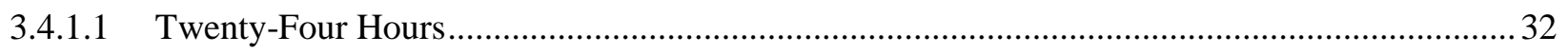

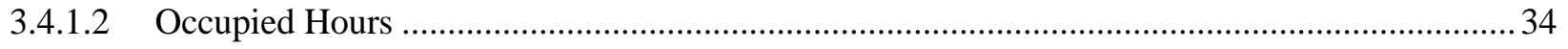

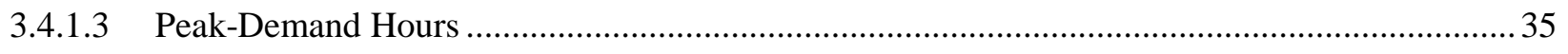

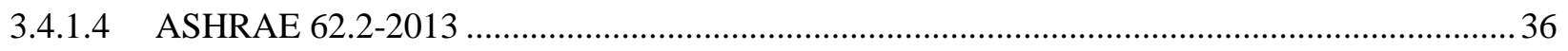

4. Conclusions

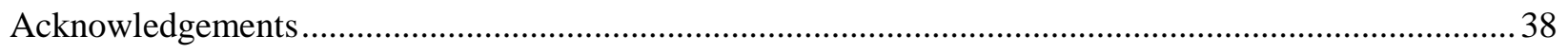

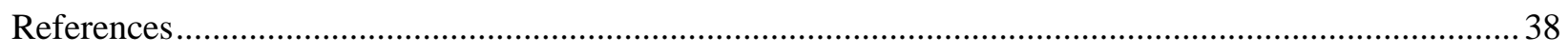

Appendix A: VOC and Aldehyde Concentrations .............................................................................. 41 


\section{List of Figures}

Figure 1. Formaldehyde concentrations, environmental conditions, and energy usage - Session A1....... 12

Figure 2. Formaldehyde concentrations, environmental conditions, and energy usage - Session A2 ....... 13

Figure 3. Formaldehyde concentrations, environmental conditions, and energy usage - Session A3....... 14

Figure 4. Formaldehyde concentrations, environmental conditions, and energy usage - Session B1....... 17

Figure 5. Formaldehyde concentrations, environmental conditions, and energy usage - Session B2 ....... 18

Figure 6. Formaldehyde concentrations, environmental conditions, and energy usage - Session B3....... 19

Figure 7. Formaldehyde concentrations, environmental conditions, and energy usage - Session C1 .......22

Figure 8. Formaldehyde concentrations, environmental conditions, and energy usage - Session C2 .......23

Figure 9. Formaldehyde concentrations, environmental conditions, and energy usage - Session C3...... 24

Figure 10. Measurements collected during the 24-hour test..........................................................26

Figure 11. Measurements during occupied hours $(5: 00 \mathrm{pm}$ to $7: 30 \mathrm{am})$. ...........................................2

Figure 12. Measurements during un-occupied hours (7:30 am to 5:00 pm).....................................28

Figure 13. Formaldehyde concentrations collected in March and July 2013 from various locations within

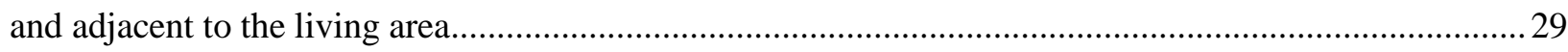

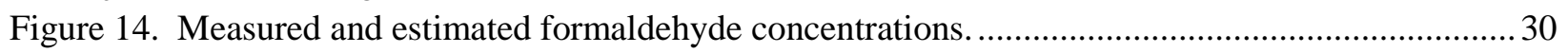

Figure 15. HVAC and indoor relative humidity estimates from 24 -hour periods. ................................... 33

Figure 16. HVAC electricity cost estimates from 24-hour periods. ….................................................. 34

Figure 17. Formaldehyde estimates from 24-hour periods............................................................ 34

Figure 18. Formaldehyde estimates during occupied hours (weekdays: 5:00 pm to 8:00 am, weekends:

whole day).

Figure 19. HVAC estimates during weekday peak-demand hours (May - Oct: 8:00 pm to 3:00 pm, Nov -

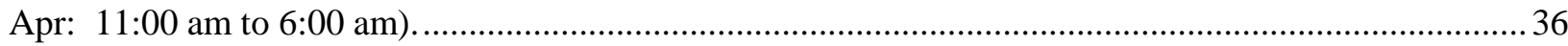




\section{List of Tables}

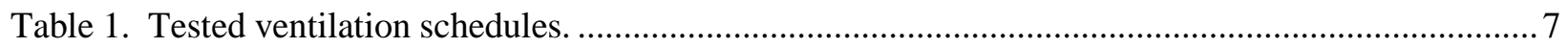

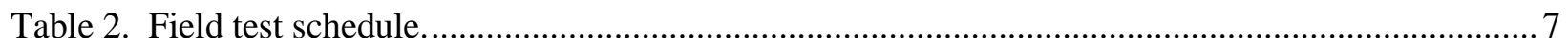

Table 3. Occupancy, continuous mechanical ventilation, occupancy-based mechanical ventilation, and air

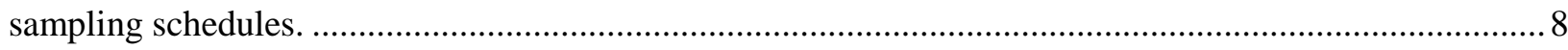

Table 4. Occupancy, utility-based mechanical ventilation, and air sampling schedules. ....................... 9

Table 5. Formaldehyde concentrations, environmental conditions, and energy usage during Session A. 15

Table 6. Formaldehyde concentrations, environmental conditions, and energy usage during Session B.. 20

Table 7. Formaldehyde concentrations, environmental conditions, and energy usage during Session C...25

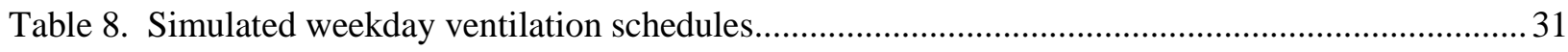

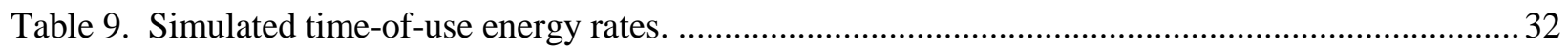

Table 10. EnergyPlus estimates for 2010 and 2013 versions of ASHRAE 62.2 ................................. 37 


\section{Executive Summary}

Mechanical ventilation is required in all homes with less than 5 air changes per hour at a pressure differential of $50 \mathrm{~Pa}$ per the 2012 International Residential Code (IRC). Ventilation rates specified in the IRC are based on ASHRAE Standard 62.2 on Ventilation and Acceptable Indoor Air Quality in Low-Rise Residential Buildings. The 62.2 standard gives the option of using either continuous or intermittent ventilation. Continuous ventilation has been the preferred technique due to its lower installation cost when provided by exhaust fans in bathrooms. In this research we examine if intermittent ventilation can outperform continuous ventilation. More specifically, our goals were to assess an occupancy-based ventilation schedule that was tailored to decrease exposure to indoor air pollutants, and a utility-based ventilation schedule that could lower energy use during peak-demand hours.

Our approach involved conducting spring and summer experiments in an unoccupied test house in east Tennessee, where we used formaldehyde concentrations as an indicator of indoor air quality. More specifically, we evaluated the effect of the following mechanical ventilation schedules per ASHRAE 62.2-2010 on indoor formaldehyde concentrations and energy use:

1. Continuous ventilation (baseline)

2. Intermittent occupancy-based ventilation

3. Intermittent utility-based ventilation

We used the field data to generate an equation to estimate formaldehyde concentrations based on total ventilation rates (i.e., mechanical and infiltration) and indoor temperature, and integrated this equation into an EnergyPlus model. The ventilation schedules we used in our simulations are listed in Table ES1 and these are based on the 2010 and 2013 versions of ASHRAE 62.2. Furthermore, we evaluated exposure to formaldehyde by presenting the average formaldehyde concentration during the hours the homes were occupied. In the simulations the occupied period was from 5:00 pm to 8:00 am during weekdays, and the entire weekend.

Table ES 1. Simulated weekday ventilation schedules. ${ }^{a}$

\begin{tabular}{|c|c|c|c|}
\hline $\begin{array}{l}\text { Ventilation } \\
\text { Schedule }\end{array}$ & $\begin{array}{c}\text { Weekday } \\
\text { Ventilation Hours }\end{array}$ & $\begin{array}{c}\text { ASHRAE 62.2-2010 } \\
\text { Mechanical Ventilation Rates } \\
\left(\mathrm{cfm}, \mathrm{h}^{-1}\right)\end{array}$ & $\begin{array}{c}\text { ASHRAE 62.2-2013 } \\
\text { Mechanical Ventilation Rates } \\
\left(\mathrm{cfm}, \mathrm{h}^{-1}\right)\end{array}$ \\
\hline Continuous & All day & $60,0.16$ & 77 \\
\hline \multirow{2}{*}{$\begin{array}{c}\text { Intermittent } \\
\text { Occupancy-based }\end{array}$} & $8: 00$ am to $5: 00 \mathrm{pm}$ & 0 & 0 \\
\hline & 5:00 pm to 8:00 am & $109,0.29$ & $169,0.45$ \\
\hline \multirow{6}{*}{$\begin{array}{l}\text { Intermittent } \\
\text { Utility-based }\end{array}$} & Summer (May - Oct) & & \\
\hline & 3:00 pm to $8: 00 \mathrm{pm}$ & 0 & 0 \\
\hline & $8: 00 \mathrm{pm}$ to $3: 00 \mathrm{pm}$ & $80,0.21$ & $105,0.28$ \\
\hline & Non-summer (Nov - Apr) & & \\
\hline & $6: 00 \mathrm{am}$ to $11: 00 \mathrm{am}$ & 0 & 0 \\
\hline & $11: 00 \mathrm{am}$ to $6: 00 \mathrm{am}$ & $80,0.21$ & $105,0.28$ \\
\hline
\end{tabular}

a. Continuous ventilation was supplied during weekends. 
The following findings should be interpreted with caution because these were derived with data from a single house that was four years old. The enclosure of this test facility is more energy efficient than what is found in the US housing stock, but it is consistent with the 2012 IRC requirements for a new home. Moreover, average formaldehyde concentrations in this test house were in the top quartile of the measurements that Offermann (2009) observed in California homes that were less than six years old.

Table ES2 summarizes the simulation results. Based on monthly relative humidity estimates using both 62.2-2010 and 62.2-2013 ventilation rates, it is likely that a humidity controller will be needed in order not to exceed the comfort level of 60\% per ASHRAE Standard 55-2013 in mixed-humid climates similar to that of east Tennessee. Moreover, annual estimates indicate that the occupancy-based ventilation led to higher annual HVAC loads than the continuous and utility-based ventilation; their respective loads were 66, 58 and $61 \mathrm{MBtu}$. Accordingly, the annual energy costs were $\$ 670, \$ 610$ and $\$ 620$, based on a time-of-use rate proposed by the Tennessee Valley Authority (TVA). These differences were primarily caused by higher sensible loads during the non-summer months (i.e., November to April) given that the occupancy-based schedule increases mechanical ventilation when outdoor temperatures are at their lowest.

Annual average formaldehyde concentration during occupied hours was the lowest with the occupancy-based schedule (32 ppb), followed by the utility-based (36 ppb) and the continuous (38 ppb) ventilation options. These results suggest that for an additional $\$ 60$ per year, occupancy-based ventilation could decrease annual average formaldehyde concentration by about $16 \%$ or $6 \mathrm{ppb}$. Given that differences in concentration between the continuous and utilitybased ventilation were negligible during the occupied hours, results suggest that indoor air quality that is equivalent to that of continuous ventilation can be supplied in a house while reducing energy consumption during peak utility periods by about $175 \mathrm{KWh}$ per year. Furthermore, results indicate that if $10 \%$ of the $2.6 \mathrm{M}$ households that TVA serves in Tennessee decided to ventilate their homes using the utility-based instead of the continuous schedule, energy savings could amount to 45 million $\mathrm{kWh}$ per year during peak hours.

As indicated in Table ES1, ventilation rates for the continuous and the utility-based schedules increased by about $30 \%$ from the 2010 to the 2013 ASHRAE 62.2 versions. This in turn could lead to an annual HVAC load and electricity cost that are about $6 \mathrm{MBtu}$ and $\$ 65$ higher, respectively. Moreover, the 2013 higher ventilation rate could translate to a reduction in annual formaldehyde concentration of about 5 to $8 \%$, or 2 to $3 \mathrm{ppb}$. With regard to the occupancy-based schedule, 62.2-2013 specifies a ventilation rate that is 55\% greater than that from 62.2-2010. This revision could cause an annual HVAC load that is higher by $14 \mathrm{MBtu}$ and HVAC electricity cost to increase by $\$ 140$. Furthermore, the new ventilation rate could lower annual formaldehyde concentrations by about $25 \%$ or $8 \mathrm{ppb}$. 
Table ES 2. EnergyPlus estimates for 2010 and 2013 versions of ASHRAE 62.2.

\begin{tabular}{|c|c|c|c|c|c|c|c|c|c|}
\hline \multirow{3}{*}{ Parameter } & \multicolumn{9}{|c|}{ Mechanical Ventilation Schedule } \\
\hline & \multicolumn{3}{|c|}{ Continuous } & \multicolumn{3}{|c|}{ Occupancy-based } & \multicolumn{3}{|c|}{ Utility-based } \\
\hline & 2010 & 2013 & $\%$ Change & 2010 & 2013 & $\%$ Change & 2010 & 2013 & $\%$ Change \\
\hline \multicolumn{10}{|l|}{ 24-hour data } \\
\hline \multicolumn{10}{|c|}{ Annual HVAC loads (MBtu) } \\
\hline Total & 58 & 63 & 9 & 66 & 80 & 21 & 61 & 67 & 10 \\
\hline Sensible & 51 & 55 & 8 & 58 & 70 & 21 & 53 & 59 & 11 \\
\hline Latent & 7 & 8 & 18 & 8 & 10 & 25 & 7 & 8 & 14 \\
\hline \multicolumn{10}{|c|}{ Indoor relative humidity (\%) } \\
\hline Aug avg $\pm S D$ & $54 \pm 3$ & $55 \pm 4$ & 2 & $56 \pm 5$ & $59 \pm 6$ & 5 & $55 \pm 4$ & $57 \pm 5$ & 4 \\
\hline $90^{\text {th }}$ ptile & 58 & 60 & 3 & 62 & 65 & 5 & 60 & 63 & 5 \\
\hline \multicolumn{10}{|c|}{ HVAC Electricity cost (\$) } \\
\hline Annual & 610 & 660 & 8 & 670 & 810 & 21 & 620 & 680 & 10 \\
\hline May - Oct & 580 & 630 & 9 & 140 & 220 & 57 & 190 & 200 & 5 \\
\hline Nov - Apr & 60 & 70 & 17 & 530 & 590 & 11 & 430 & 480 & 12 \\
\hline \multicolumn{10}{|c|}{ Formaldehyde concentration (ppb) } \\
\hline Annual & $38 \pm 9$ & $36 \pm 9$ & -5 & $35 \pm 10$ & $29 \pm 11$ & -17 & $37 \pm 9$ & $34 \pm 9$ & -8 \\
\hline May - Oct & 45 & 42 & -7 & 41 & 35 & -15 & 43 & 41 & -5 \\
\hline Nov - Apr & 31 & 29 & -6 & 28 & 22 & -21 & 30 & 27 & -10 \\
\hline \multicolumn{10}{|c|}{ Occupied-hour data } \\
\hline \multicolumn{10}{|c|}{ Formaldehyde concentration (ppb) } \\
\hline Annual & $38 \pm 9$ & $36 \pm 9$ & -5 & $32 \pm 8$ & $24 \pm 8$ & -25 & $36 \pm 9$ & $33 \pm 9$ & -8 \\
\hline May - Oct & 45 & 42 & -7 & 39 & 31 & -21 & 43 & 40 & -7 \\
\hline Nov - Apr & 31 & 29 & -6 & 25 & 18 & -28 & 29 & 26 & -10 \\
\hline \multicolumn{10}{|c|}{ Peak-demand hours } \\
\hline \multicolumn{10}{|c|}{ Annual HVAC loads (MBtu) } \\
\hline Total & 12 & 13 & 8 & 12 & 14 & 17 & 10 & 10 & 0 \\
\hline
\end{tabular}




\section{Introduction}

Intermittent ventilation has the potential to outperform continuous ventilation in homes. Possible benefits include decreased occupant exposure to air pollutants; lower heating, ventilation, and air conditioning (HVAC) loads; and reduced energy use during peak-demand hours. Although various studies have been conducted on these benefits (Mortensen et al. 2011; Sherman et al. 2004; Sherman et al. 2010), all of these have been based on simulations. These need to be supplemented with field data that will enhance our understanding of the temporal variations of indoor air contaminants. This information will demonstrate to homeowners, building scientists, technical committees, and utilities that carefully planned intermittent ventilation schedules can either improve or maintain indoor air quality in an energy efficient manner when compared to continuous ventilation.

The present research aimed to fill the aforementioned knowledge gaps. To this end, the objective of this work was to evaluate the effects from intermittent ventilation per ASHRAE Standard 62.2 on energy use and indoor air quality (IAQ), while using continuous ventilation as the baseline. More specifically, our goals were to assess an occupancy-based schedule that was tailored to decrease exposure to indoor air pollutants, and a utility-based schedule that could lower energy use during peak-demand hours.

To meet these goals, we conducted evaluations at an unoccupied test house in east Tennessee. In the initial survey, air samples were analyzed for volatile organic compounds (VOCs) and aldehydes typically found in residences. Formaldehyde was the only chemical found to be at levels of concern; therefore, we used this pollutant as the indicator of indoor air quality in this research. This is consistent with the findings by Hun et al. (2013), and with recommendations by Sherman and Hodgson (2004) to utilize formaldehyde as the basis for residential ventilation rates given its pervasiveness indoors and the relatively high cancer risks that have been linked to exposures to this pollutant (Hun et al. 2009; Logue et al. 2011).

The 2010 version of ASHRAE 62.2 was in effect during the planning phase of this project. Consequently, the ventilation rates that we evaluated in our field experiments are based on this version. However, we included in our simulations the ventilation rates prescribed by 62.2-2013 given that this document was issued before the completion of this report.

\section{Methodology}

\subsection{Test House}

The test facility is located in east Tennessee (DOE climate zone 4) and was built in 2009. The house is comprised of two stories, three bedrooms, and a bonus room. The living areas have a total footprint of $2,400 \mathrm{ft}^{2}$ and a volume of $22,430 \mathrm{ft}^{3}$. Exterior walls were framed with $2 \times 6$ studs at 24 " on center. In these walls, the exterior board consisted of $1 / 2$ "-thick structural insulated sheathing $\left(\mathrm{R}-3 \mathrm{~h} \cdot \mathrm{ft}^{2} \cdot{ }^{\circ} \mathrm{F} / \mathrm{Btu}\right)$ that was composed of a water-resistive overlay, polyisocyanurate foam core and a thermo-ply layer. One inch-thick, closed-cell foam was sprayed on the exterior sheathing and the rest of the cavity was filled with blown-in fiberglass.

The total R-value of the insulation in the exterior walls was $22 \mathrm{~h} \cdot \mathrm{ft}^{2} \cdot{ }^{\circ} \mathrm{F} / \mathrm{Btu}$, while the fiberglass 
insulation that was sprayed on the attic floor had an R-value of $50 \mathrm{~h} \cdot \mathrm{ft}^{2} \cdot{ }^{\circ} \mathrm{F} / \mathrm{Btu}$. A blower door test indicated that the house had a leakage rate of 2.4 air changes per hour at a pressure differential of $50 \mathrm{~Pa}$ (ACH50). Christian et al. (2010) provide more details about the envelope system in this house.

Every room in the test house included pre-owned furniture. The facility was also equipped with an occupancy simulation system that allowed researchers to evaluate its contribution to energy use. The basis of the occupancy schedule was the Building America Research Benchmark Definition (Hendron and Engebrecht 2010). Boudreaux et al. (2012) describe the daily schedules that were followed with appliances and lighting. Additionally, sensible and latent loads were regulated through heat and moisture sources such as showers.

The heating, ventilation, and air conditioning (HVAC) system in the test house consisted of a 2 ton air source heat pump. The unit had a measured average Heating Seasonal Performance Factor $(\mathrm{HSPF})$ of $8.1 \pm 1.3(\mathrm{Btu} / \mathrm{Wh})$ [Coefficient of Performance $(\mathrm{COP})=2.4 \pm 0.4$ ], and a measured Seasonal Energy Efficiency Ratio (SEER) of $12 \pm 2.6(\mathrm{Btu} / \mathrm{Wh})(\mathrm{COP}=3.5 \pm 0.8)$. The thermostat was on cooling mode with a setpoint of $75^{\circ} \mathrm{F}$ throughout the study. In order to control the mechanical ventilation rate in the present study, a portable blower (Lennox HEPA60) was installed between the outdoor air intake and a supply duct that branched out throughout the house. Supply ventilation was selected because research by Hun et al. (2013), and Rudd and Bergey (2013) indicated exhaust ventilation was not as effective in reducing indoor concentrations of formaldehyde. A meter (Veltron DPT 2500) between the blower and the supply duct measured the outdoor airflow rate. The power usage of the blower at the evaluated low rates was: $10.7 \mathrm{~W}$ at $60 \mathrm{cfm}, 20 \mathrm{~W}$ at $80 \mathrm{cfm}$, and $46.4 \mathrm{~W}$ at $137 \mathrm{cfm}$.

\subsection{Measurements}

\subsubsection{Volatile Organic Compounds and Formaldehyde}

VOCs and formaldehyde were monitored with active sampling. VOCs were collected using Supelco thermal desorption tubes packed with Carbotrap. Formaldehyde was sampled with SKC 2,4-dinitrophenylhydrazine (DNPH) silica gel cartridges with potassium iodide ozone scrubbers. Air was drawn through the Supelco tubes and DNPH cartridges with sampling pumps; flow rates were measured at the beginning and end of a monitoring session with a NIST traceable calibrated positive displacement dry calibrator (Bios Defender 530). For monitoring periods that were greater than 4 hours, air was sampled at a rate of $\sim 200 \mathrm{cc} / \mathrm{min}$. In the case of shorter evaluation periods, the sampling rate was increased to $\sim 500 \mathrm{cc} / \mathrm{min}$. Analyses were performed at Matrix Analytical Laboratories, Inc. in Farmers Branch, TX. For formaldehyde and other aldehydes, most air samples were analyzed following the "Shake-a-Vial" extraction method using $5 \mathrm{~mL}$ of acetonitrile (SKC 2008), while a few of the initial analyses were conducted using a single pass extraction method with $5 \mathrm{~mL}$ of acetonitrile as specified in the Environmental Protection Agency method EPA TO-11a for formaldehyde (EPA 1999a). High pressure liquid chromatography (HPLC) as specified in EPA TO-11a was utilized to quantify the mass of formaldehyde and other aldehyde derivatives extracted from the DNPH cartridges. The relative uncertainty of the mass of formaldehyde collected in each DNPH cartridge was estimated based on four duplicate 
samples collected in the field, which showed a relative uncertainty of $4.5 \%$ at a $95 \%$ confidence level. A modified version of EPA TO-17 was used for VOC analyses (EPA 1999b).

Air samples were collected indoors and outdoors. Indoor monitoring was conducted in the main living area on the first floor, and, on two occasions, at other locations that could be acting as main sources of pollutants (e.g., garage, attic). Outdoor measurements were collected from the covered front porch of the house, and the sampling period was limited to noon until 4:00 pm because warmer afternoon temperatures decreased the potential of condensation that could lead to congealment of the sorbent in the DNPH tubes.

\subsubsection{Environmental Conditions}

Indoor temperature and relative humidity were monitored with Honeywell 192-103LET-A01 and Honeywell HIH-4000 sensors, respectively. Outdoor temperature and relative humidity measurements were gathered with a Campbell Scientific CS215 sensor. Wind speed and direction were collected with a WindSonic monitor from Gill Instruments. Indoor data were reported every 15 minutes, while outdoor parameters were recorded every minute.

\subsubsection{Ventilation Rates}

Ventilation or air exchange rates (AER) were estimated with the tracer gas decay method. Realtime data were sampled and analyzed with an Innova 1303 multipoint sampler/doser and an Innova 1412 photoacoustic gas analyzer, respectively. The tracer gases used were 1,1,1,2tetrafluoroethane $\left(\mathrm{C}_{2} \mathrm{H}_{2} \mathrm{~F}_{4}\right.$, also known as the freon $\left.\mathrm{R} 134 \mathrm{a}\right)$; its minimum detection limit at $68^{\circ} \mathrm{F}$ is $11 \mathrm{ppb}$. In addition to R134a, the analyzer also monitored water vapor and other fluorinated compounds to compensate for interference. Tracer gas was sampled every two minutes, and sampling time varied per test and lasted a minimum of two hours. Although the HVAC fan only ran when cooling or heating was required, the air in the house was relatively well mixed because simultaneous sampling of tracer gas from the $1^{\text {st }}$ and $2^{\text {nd }}$ floors indicated that concentrations at these locations were within $10 \%$ of each other.

Confidence limits were determined by the method described in ASTM E 741-00 (Reapproved 2006), Standard Test Method for Determining Air Change in a Single Zone by Means of a Tracer Gas Dilution. The average confidence limit on AER was +/- 2.2\% based on 31 samples.

\subsection{Field Test Protocol}

Field tests focused on examining the effect of three mechanical ventilation schedules that comply with ASHRAE 62.2-2010 on indoor formaldehyde concentrations. The ventilation rates were estimated based on requirements for a three bedroom house with a floor area of $2,400 \mathrm{ft}^{2}$. As shown in Table 1, the effects from continuous ventilation $\left(60 \mathrm{cfm}, 0.16 \mathrm{~h}^{-1}\right)$ were compared against those from two intermittent ventilation schedules: occupancy-based and utility-based. The occupancy-based schedule attempted to lessen exposure to formaldehyde by maximizing ventilation during the hours when people are in their homes, i.e., $137 \mathrm{cfm}\left(0.37 \mathrm{~h}^{-1}\right)$ from 5:00 pm to 7:30 am, and shut down the supply of fresh air the rest of the time. The utility-based schedule turned off mechanical ventilation for five hours during a fraction of the summer peak demand hours reported by the Tennessee Valley Authority (TVA), that is, from 3:00 pm to 8:00 $\mathrm{pm}$; and compensated for potential increases in formaldehyde concentration by providing $80 \mathrm{cfm}$ $\left(0.21 \mathrm{~h}^{-1}\right)$ of outdoor air during the remaining hours. 
Table 1. Tested ventilation schedules.

\begin{tabular}{|c|c|c|c|}
\hline $\begin{array}{l}\text { Ventilation } \\
\text { Schedule }\end{array}$ & Time & $\begin{array}{l}\text { Mechanical Ventilation Rate } \\
\left(\mathrm{cfm}, \mathrm{h}^{-1}\right)\end{array}$ & $\begin{array}{l}\text { Mechanically Supplied Outdoor Air } \\
\text { (ft3/day) }\end{array}$ \\
\hline Continuous & All day & $60,0.16$ & 86,400 \\
\hline \multirow{2}{*}{$\begin{array}{c}\text { Intermittent } \\
\text { Occupancy-based }\end{array}$} & $7: 30^{\mathrm{a}}$ am to $5: 00 \mathrm{pm}$ & 0 & 0 \\
\hline & $5: 00 \mathrm{pm}$ to $7: 30 \mathrm{a} a m$ & $137,0.37$ & 119,200 \\
\hline \multirow{2}{*}{$\begin{array}{l}\text { Intermittent } \\
\text { Utility-based }\end{array}$} & $3: 00 \mathrm{pm}$ to $8: 00 \mathrm{pm}$ & 0 & 0 \\
\hline & $8: 00 \mathrm{pm}$ to $3: 00 \mathrm{pm}$ & $80,0.21$ & 91,200 \\
\hline
\end{tabular}

a. 7:30 am was used in the field tests. For simplicity, 8:00 am was used in the EnergyPlus models.

The mechanical ventilation schedules were assessed during the spring and summer of 2013 in order to capture seasonal effects. As described in Table 2, Session A was conducted in the spring, while Sessions B and C were performed in the summer. Every session was composed of three Tests where each of the ventilation schedules was examined. All Tests lasted one day, although the required ventilation rate was set the day before so that formaldehyde had reached a pseudo steady-state concentration by the time the evaluation began. Tables 3 and 4 summarize the times when air was sampled throughout most of the Tests based on the ventilation schedule being evaluated. These Tables show the final air sampling schedule that was generated after results from Sessions A1 and A2 indicated that more data points were needed. One-hour samples were collected to acquire information on concentration buildup after the mechanical ventilation was shut down, and on formaldehyde reduction after mechanical ventilation was turned on. Indoor air was also monitored for longer periods to examine formaldehyde concentrations during the occupied (14.5-hr sample) and non-occupied hours (9.5-hr sample). To estimate the total ventilation rate (i.e., infiltration plus mechanical) in each of the evaluations, a tracer gas test was performed each time the mechanical ventilation rate was changed.

Table 2. Field test schedule.

\begin{tabular}{|c|cc|cc|cc|}
\hline $\begin{array}{c}\text { Ventilation } \\
\text { Schedule }\end{array}$ & $\begin{array}{c}\text { Session A } \\
\text { Tests }\end{array}$ & Dates & \multicolumn{2}{|c|}{$\begin{array}{c}\text { Session B } \\
\text { Tests }\end{array}$} & Dates & \multicolumn{2}{|c|}{$\begin{array}{c}\text { Session C } \\
\text { Tests }\end{array}$} & Dates \\
\hline Continuous & A1 & $5 / 2 / 13-5 / 3 / 13$ & B1 & $6 / 22 / 13-6 / 23 / 13$ & C1 & $7 / 10 / 13-7 / 11 / 13$ \\
\hline $\begin{array}{c}\text { Intermittent } \\
\text { Occupancy-based }\end{array}$ & A2 & $5 / 8 / 13-5 / 9 / 13$ & B2 & $7 / 5 / 13-7 / 6 / 13$ & C2 & $7 / 12 / 13-7 / 13 / 13$ \\
\hline $\begin{array}{c}\text { Intermittent } \\
\text { Utility-based }\end{array}$ & A3 & $5 / 24 / 13-5 / 25 / 13$ & B3 & $7 / 1 / 13-7 / 2 / 13$ & C3 & $7 / 14 / 13-7 / 15 / 13$ \\
\hline
\end{tabular}


Table 3. Occupancy, continuous mechanical ventilation, occupancy-based mechanical ventilation, and air sampling schedules.

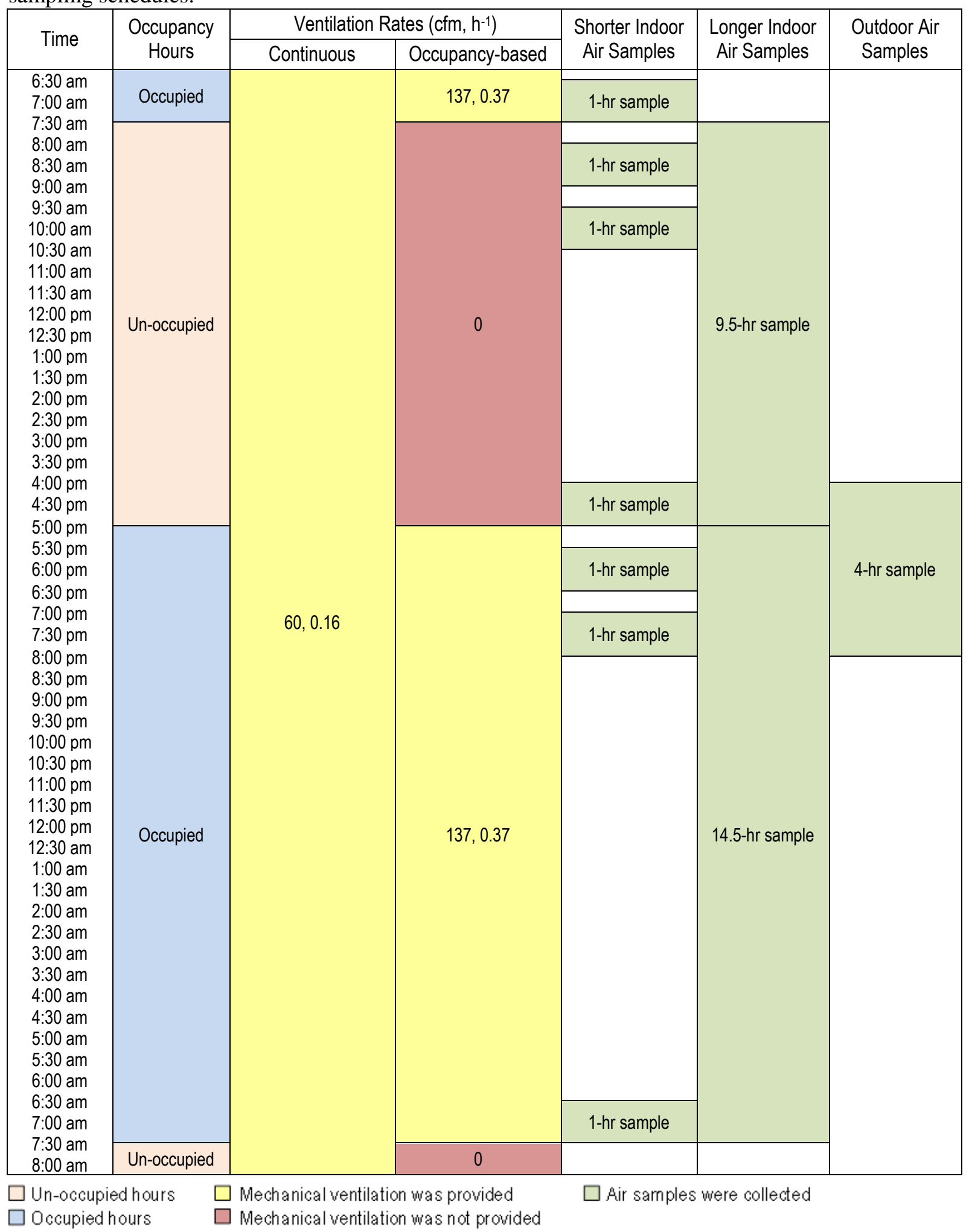


Table 4. Occupancy, utility-based mechanical ventilation, and air sampling schedules.

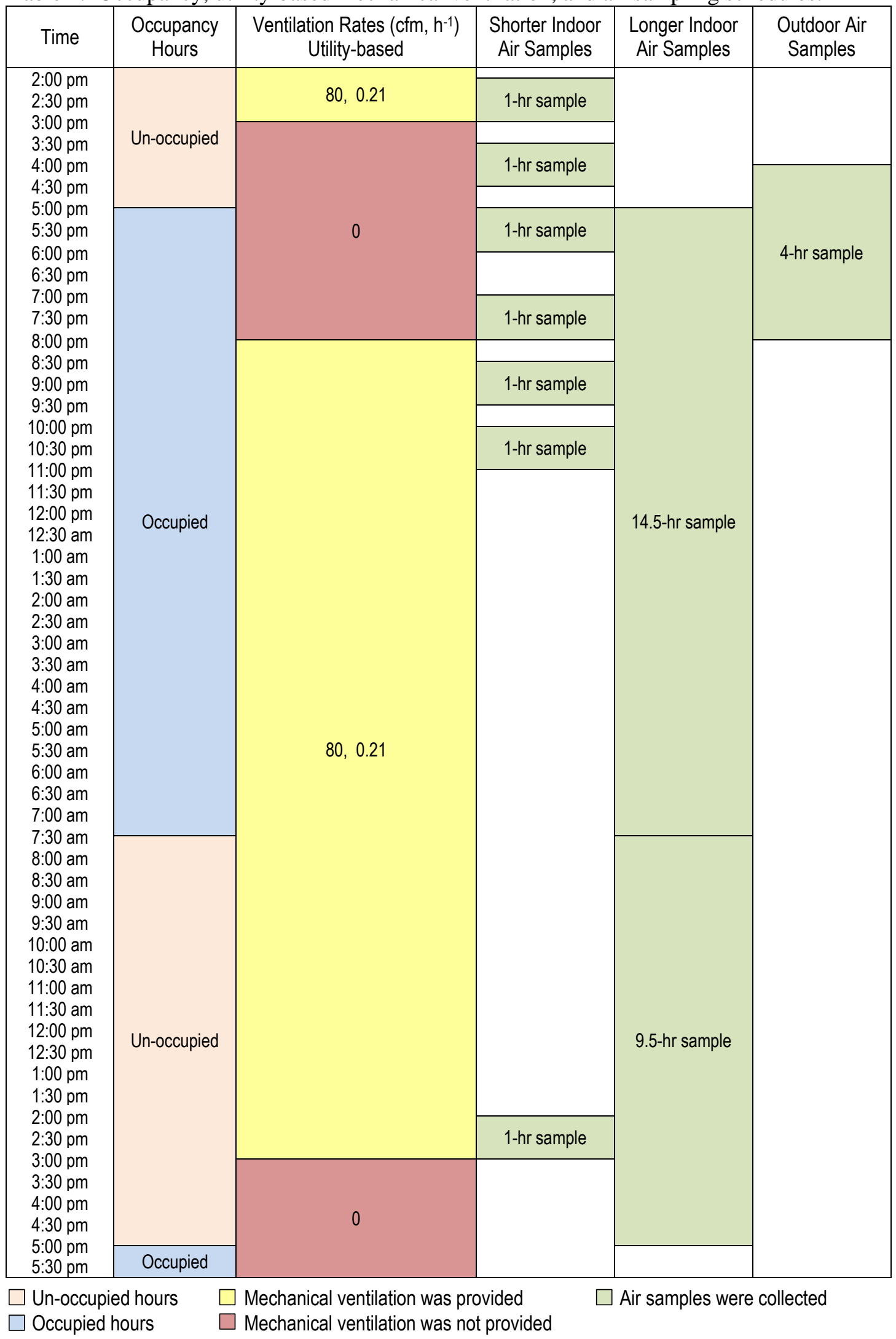




\subsection{Multivariate Regressions}

Microsoft Excel 2010 was used to conduct multivariate regressions and generate a model to predict indoor formaldehyde concentrations. The formaldehyde measurements that were utilized were the one-hour samples that were collected after the test house had a set mechanical ventilation rate for at least 9 hours; data indicate that steady-state concentrations had been reached after this amount of time. Variables considered in the regressions were indoor temperature and total ventilation rates based on results from Hun et al. (2013). One-hour averages were used with all of these variables except for total ventilation because its evaluation periods were longer. Due to the fairly tight construction of the test house, total ventilation measurements were relatively stable as long as mechanical ventilation rates remained steady and changes in outdoor conditions were not large. Sorption of formaldehyde to storage materials were not included in the regression models because this effort was beyond the scope of this project.

\subsection{Simulations}

EnergyPlus models were generated using version 7.2.0.006. The Flow Coefficient model, referred to by ASHRAE as the "Enhanced" or "AIM-2" was selected in EnergyPlus to estimate infiltration rates based on Walker and Wilson (1998), ASHRAE Handbook of Fundamentals (ASHRAE 2001, 2005, 2013), and EnergyPlus Engineering Reference (DOE 2013). The flow coefficient "c" was calculated using a least squares fit of infiltration rate, indoor-to-outdoor temperature differential, and wind speed data that were collected while the mechanical ventilation system was shut down. The authors are aware that other infiltration modeling programs may provide more accurate infiltration results than EnergyPlus and that enhancements to this simulation tool may be appropriate; however, this was beyond the scope of this project.

The derived multivariate equation was used with the EnergyPlus models to predict hourly formaldehyde concentrations, indoor relative humidity, HVAC loads, and energy cost.

\section{Results and Discussion}

\subsection{Identification of Pollutants of Concern}

An initial survey was conducted in December 2012 to identify pollutants of concern. VOC and aldehyde concentrations from this survey are presented in Appendix A. Results indicate that the monitored VOCs were well below the recommended exposure levels (REL) set by the National Institute for Occupational Safety and Health (NIOSH) and/or the state of California Office of Environmental and Health Hazard Assessment (OEHHA). This is likely because many of the typical sources that emit these compounds (e.g., gasoline, solvents, fragrances, cleaners) are not present in unoccupied houses in significant quantities.

Among the aldehydes that were monitored, only formaldehyde exceeded the RELs set by NIOSH $(10-\mathrm{hr}$ exposure $=16 \mathrm{ppb})$ and OEHHA $(8-\mathrm{hr}$ exposure $=7.3 \mathrm{ppb})$, which are the strictest recommended levels worldwide. Other RELs include: Canada $=40 \mathrm{ppb}(8-\mathrm{hr})$, Norway $=50$ ppb (24-hr), and World Health Organization (WHO) $=81 \mathrm{ppb}$ (chronic exposure). The measured 24-hr time-weighted average (TWA) formaldehyde concentration during the initial survey was 
$38 \mathrm{ppb}$. Consequently, it was determined that formaldehyde would be used as an indicator of adequate indoor air quality throughout this research. This is in agreement with findings by Hun et al. (2013), and with recommendations by Sherman and Hodgson (2004) to utilize formaldehyde as a basis for residential ventilation rates given its pervasiveness indoors.

\subsection{Field Data}

The following Sections describe results from Sessions A, B and C. Note that the interpretation of the presented HVAC energy usage and formaldehyde concentrations should take into account that these are highly dependent on outdoor and indoor temperature. Section 3.4 covers results from simulations where several of the influential variables on energy usage and formaldehyde concentrations are simultaneously considered.

\subsubsection{Session A}

Formaldehyde concentrations, indoor and outdoor conditions, ventilation rates, and energy usage from Tests A1, A2 and A3 are described in Figures 1 through 3. Averages from these data are summarized in Table 5. The 24-hr average indoor temperature $\left(T_{i n}\right)$ during these tests was about $72{ }^{\circ} \mathrm{F}$ because the corresponding outdoor average temperatures $\left(T_{\text {out }}\right)$ ranged between 58 and 65 ${ }^{\circ} \mathrm{F}$, and because the heater was not in operation given that the thermostat was set to cooling mode. Consequently, the HVAC energy used was less than $3.9 \mathrm{kWh}$. The reported HVAC energy used in each of the three ventilation schedules do not lend themselves for comparison purposes because $T_{\text {out }}$ values from these tests were significantly different. Indoor relative humidity $\left(\mathrm{RH}_{\text {in }}\right)$ was somewhat steady throughout each of the tests (i.e., standard deviation $\sim 1.5 \%$ ) because the air was not being dehumidified by the HVAC system. The 24-hr average $R H_{\text {in }}$ ranged from 46 to $55 \%$, where the former value was influenced by a cold front with relatively dry air.

Targeted mechanical ventilation rates were adequately met as indicated in Table 5. Infiltration can be calculated using the measured data given that, with unbalanced systems, total ventilation has been estimated as the root sum square of the mechanical and infiltration (ASHRAE 1993). Results indicate that infiltration tended to be the highest when the mechanical ventilation system was not in operation; these rates were $31 \mathrm{cfm}\left(0.08 \mathrm{~h}^{-1}\right)$ during Test $\mathrm{A} 2$ and $28 \mathrm{cfm}\left(0.07 \mathrm{~h}^{-1}\right)$ in Test A3. Variations in infiltration rates were likely due to changes in wind speed, as well as the indoor-to-outdoor temperature differential.

As described in Figure 1 and Table 5, the 24-hr air sample collected during Test A1 measured an indoor formaldehyde concentration $\left(C_{i n}\right)$ of $40 \mathrm{ppb}$ while total ventilation was $65 \mathrm{cfm}\left(0.18 \mathrm{~h}^{-1}\right)$. One-hour samples from Test A1 fluctuated around the 24-hr measurement. One-hour samples from Test A2 and shown in Figure 2 indicate that $C_{i n}$ increased from 13 to $52 \mathrm{ppb}$ after the mechanical ventilation was turned off throughout the un-occupied hours. Concentration diminished to $17 \mathrm{ppb}$ after the mechanical ventilation system was turned on and a total ventilation rate of $143 \mathrm{cfm}\left(0.38 \mathrm{~h}^{-1}\right)$ was provided. Note that the low formaldehyde concentrations that were obtained during the occupied hours were influenced by the relatively low indoor temperatures as shown in Figure 2. In Test A3, Figure 3 illustrates how 1-hr $C_{\text {in }}$ values built up from 43 to about $54 \mathrm{ppb}$ while ventilation was shut down during the peak energy demand period. Afterwards, concentrations lowered to $36 \mathrm{ppb}$ with $82 \mathrm{cfm}\left(0.22 \mathrm{~h}^{-1}\right)$ total ventilation. 


\section{Test A1}
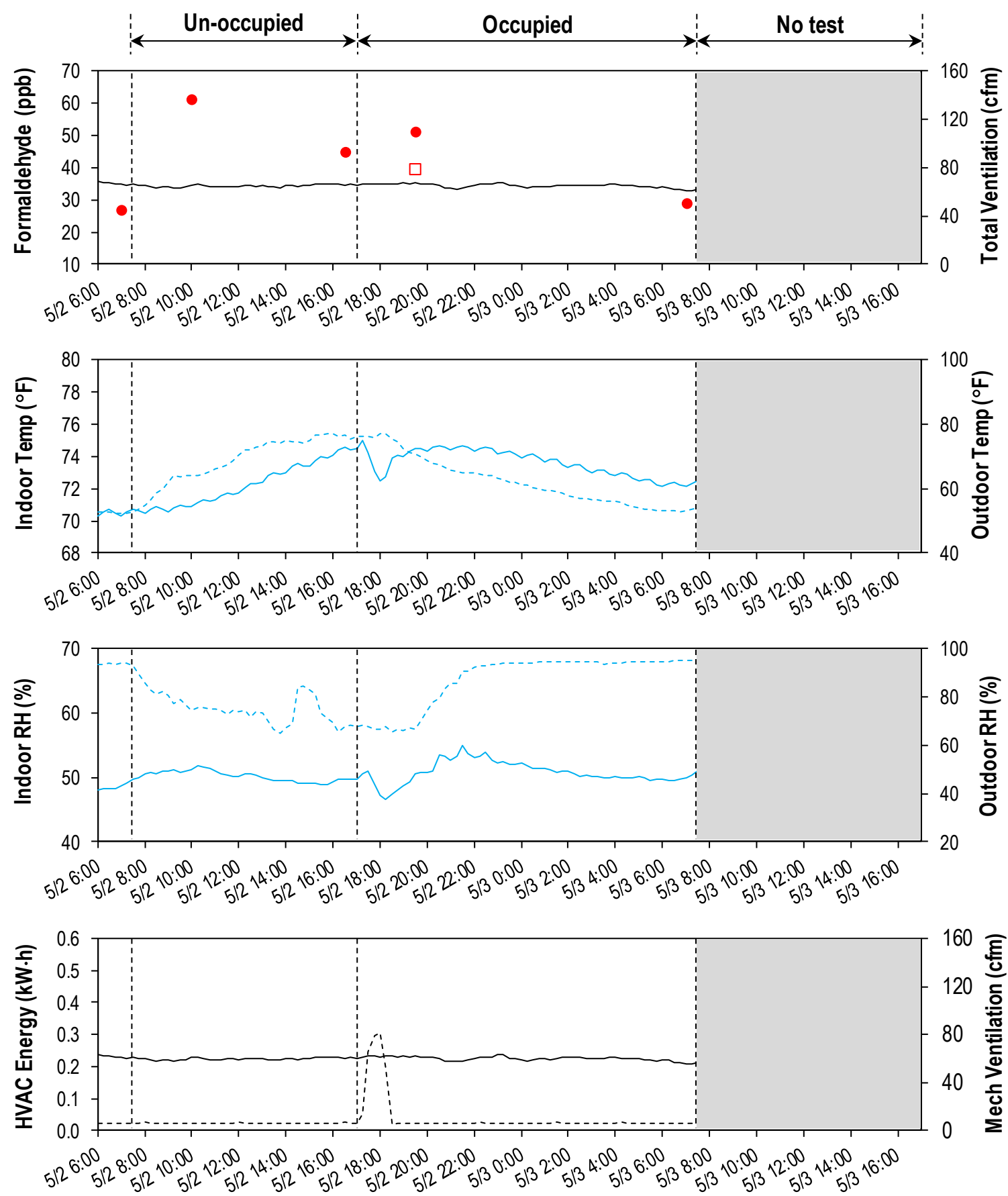

- 1-hr avg formaldehyde

$$
\begin{aligned}
& \text { - Indoor conditions } \square \text { Avg total ventilation }=65 \mathrm{~cm}\left(0.18 \mathrm{~h}^{-1}\right) \\
& - \text { - Outdoor conditions } \\
& \text { - Ventilation }
\end{aligned}
$$$$
\text { 24-hr avg formaldehyde }
$$

Figure 1. Formaldehyde concentrations, environmental conditions, and energy usage - Session A1. 


\section{Test A2}
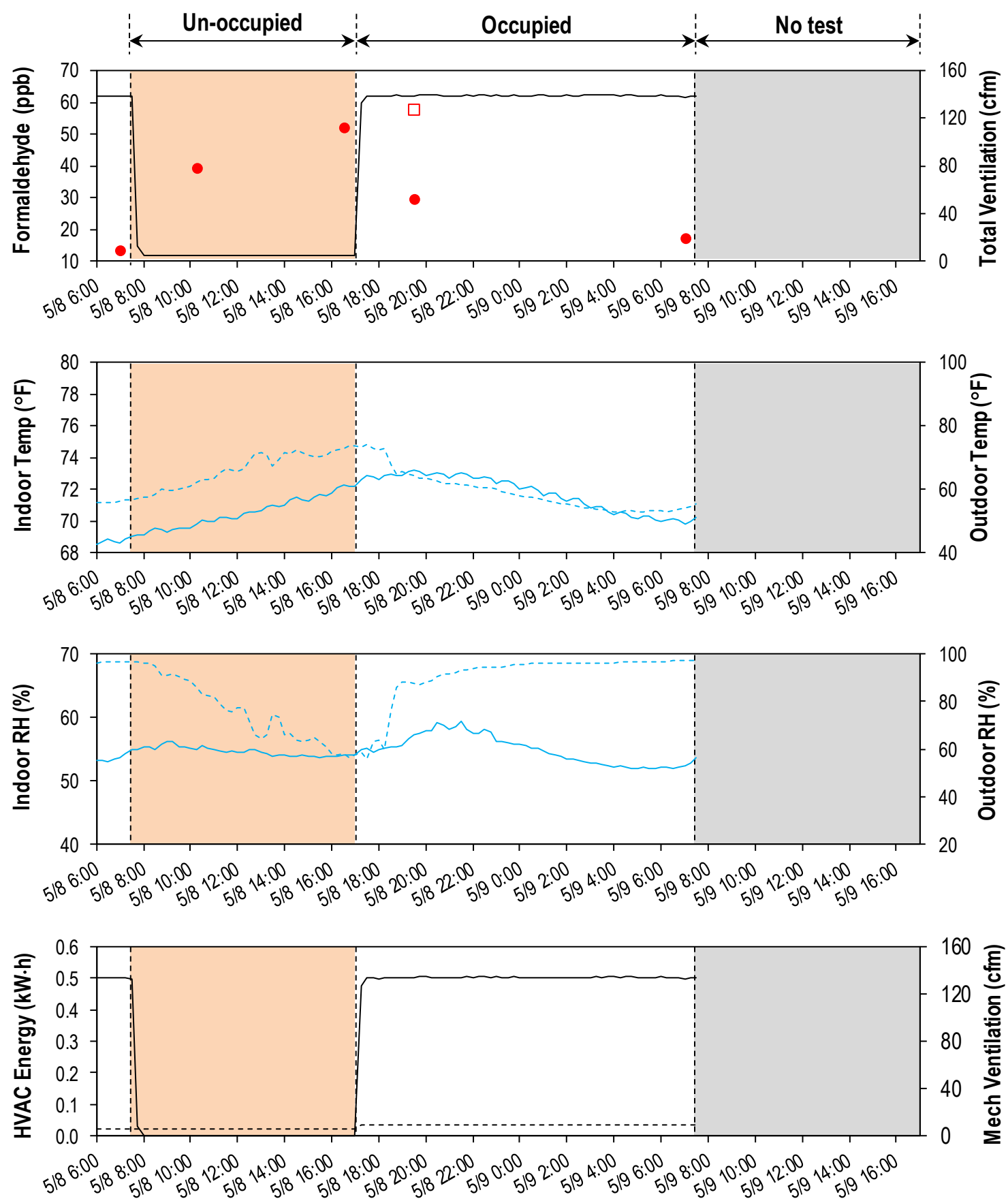

- 1-hr avg formaldehyde

24-hr avg formaldehyde

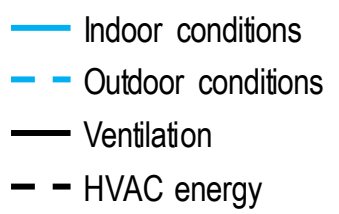

- Indoor conditions

- = Outdoor conditions

- - HVAC energy $\square$ Avg total ventilation $=143 \mathrm{~cm}\left(0.38 \mathrm{~h}^{-1}\right)$ Avg mech ventilation $=134 \mathrm{cfm}\left(0.36 \mathrm{~h}^{-1}\right)$

$\square$ Avg total ventilation $=31.2 \mathrm{~cm}\left(0.08 \mathrm{~h}^{-1}\right)$ Avg mech ventilation $=0.3 \mathrm{~cm}\left(0.001 \mathrm{~h}^{-1}\right)$

Figure 2. Formaldehyde concentrations, environmental conditions, and energy usage - Session A2. 


\section{Test A3}
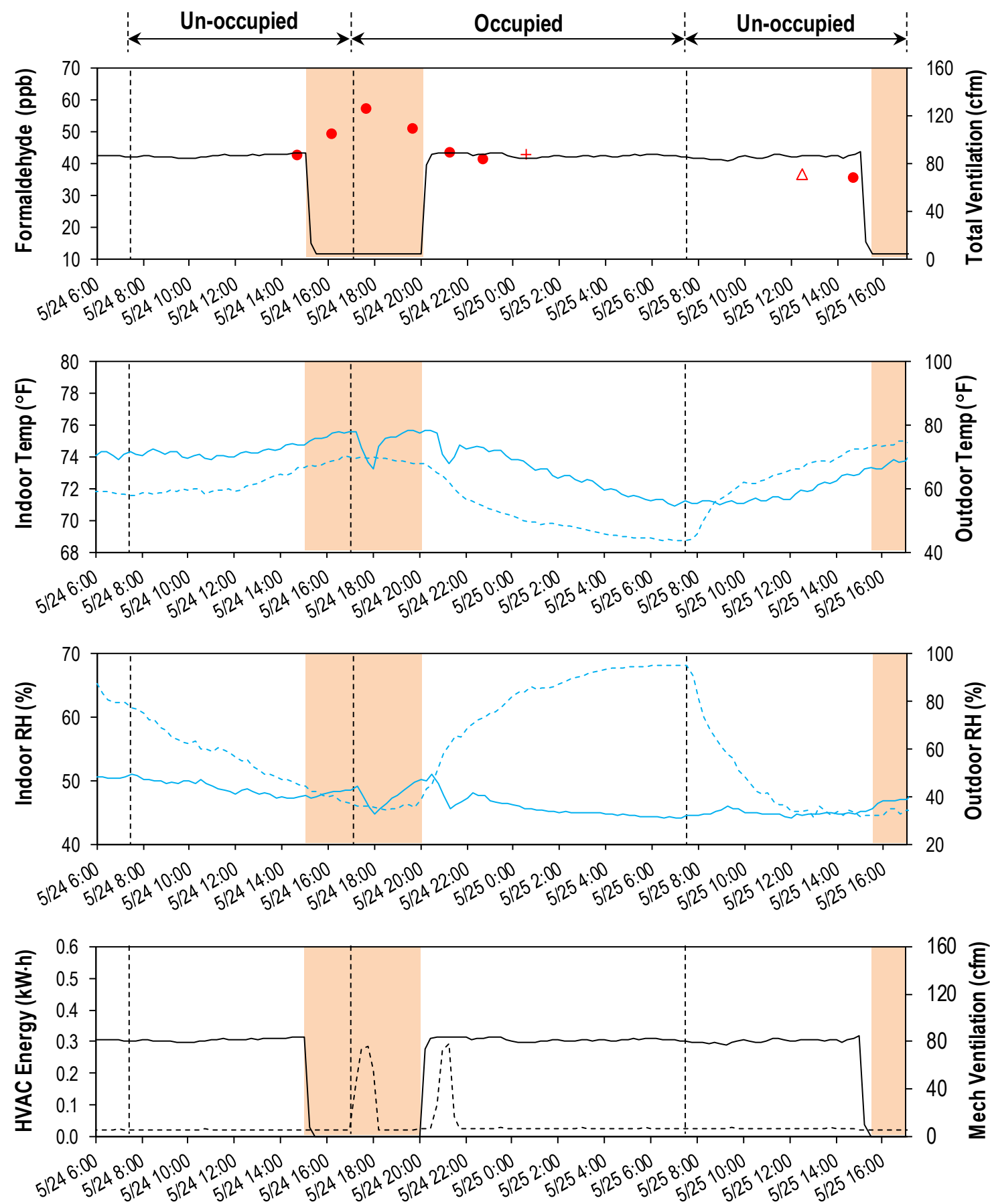

- 1-hr avg formaldehyde

$\triangle$ Avg formaldehyde un-occupied hours

+ Avg formaldehyde occupied hours
- Indoor conditions

- - Outdoor conditions

- Ventilation - - HVAC energy $\square$ Avg total ventilation $=81.5 \mathrm{~cm}\left(0.22 \mathrm{~h}^{-1}\right)$ Avg mech ventilation $=80.1 \mathrm{~cm}\left(0.21 \mathrm{~h}^{-1}\right)$

$\square$ Avg total ventilation $=27.6 \mathrm{~cm}\left(0.07 \mathrm{~h}^{-1}\right)$ Avg mech ventilation $=0 \mathrm{~cm}\left(0 \mathrm{~h}^{-1}\right)$

Figure 3. Formaldehyde concentrations, environmental conditions, and energy usage - Session A3. 
Table 5. Formaldehyde concentrations, environmental conditions, and energy usage during Session A.

\begin{tabular}{|c|c|c|c|c|c|c|c|c|c|c|c|c|c|}
\hline & \multicolumn{4}{|c|}{ Test A1: $5 / 2 / 13-5 / 3 / 13$} & \multicolumn{4}{|c|}{ Test A2: $5 / 8 / 13-5 / 9 / 13$} & \multicolumn{5}{|c|}{ Test A3: 5/24/13 - 5/25/13 } \\
\hline & Un-occupied & Occupied & Peak & 24-hr & Un-occupied & Occupied & Peak & 24-hr & Un-occupied & Occupied & Non-Peak & Peak & 24-hr \\
\hline \multicolumn{14}{|c|}{ Indoor and Outdoor Parameters } \\
\hline$C_{\text {in }}(p p b)$ & - & - & - & $40^{a}$ & - & - & - & $58^{a}$ & 37 & 43 & - & - & - \\
\hline $\mathrm{C}_{\text {out }}(\mathrm{ppb})$ & - & - & - & $1.6^{b}$ & - & - & - & - & - & - & - & - & $1 \mathrm{~b}$ \\
\hline $\mathrm{T}_{\text {in }}\left({ }^{\circ} \mathrm{F}\right)$ & $72.1 \pm 1.3$ & $73.6 \pm 0.9$ & $74 \pm 0.6$ & $73 \pm 1.3$ & $70.6 \pm 1$ & $71.7 \pm 1.1$ & $72.4 \pm 0.6$ & $71.3 \pm 1.2$ & $72.3 \pm 1.6$ & $73.4 \pm 1.4$ & $72.5 \pm 1.3$ & $75 \pm 0.7$ & $73 \pm 1.6$ \\
\hline $\mathrm{T}_{\text {out }}\left({ }^{\circ} \mathrm{F}\right)$ & $68.6 \pm 7.2$ & $62.3 \pm 7.5$ & $75.1 \pm 1.2$ & $64.8 \pm 8$ & $66 \pm 5.4$ & $59.3 \pm 6.2$ & $70.1 \pm 3.5$ & $61.9 \pm 6.7$ & $64.8 \pm 6.3$ & $53.8 \pm 9.5$ & $55.4 \pm 9.4$ & $68.9 \pm 0.9$ & $58.1 \pm 9.9$ \\
\hline $\mathrm{RH}_{\text {in }}(\%)$ & $50.2 \pm 0.8$ & $50.7 \pm 1.7$ & $49.2 \pm 1.1$ & $50.5 \pm 1.4$ & $54.6 \pm 0.7$ & $54.8 \pm 2.3$ & $54.9 \pm 1.1$ & $54.8 \pm 1.8$ & $45.5 \pm 1.3$ & $46.2 \pm 1.8$ & $45.4 \pm 1.4$ & $47.6 \pm 1.2$ & $45.9 \pm 1.6$ \\
\hline $\mathrm{RH}_{\text {out }}(\%)$ & $75.6 \pm 6.6$ & $87 \pm 11$ & $69.2 \pm 4.6$ & $82.5 \pm 11$ & $76.3 \pm 13$ & $90.5 \pm 11$ & $67.7 \pm 12$ & $84.8 \pm 14$ & $46.1 \pm 16.4$ & $71.9 \pm 23$ & $62.9 \pm 23.8$ & $37.6 \pm 2.8$ & $61.7 \pm 24.2$ \\
\hline \multicolumn{14}{|c|}{ Ventilation Rates (cfm, h-1) } \\
\hline Mechanical c & $60,0.16$ & $60,0.16$ & - & $60,0.16$ & 0 & $134,0.36$ & - & $81,0.22$ & $67.1,0.18$ & $63.4,0.17$ & $80.1,0.21$ & 0 & $64.8,0.17$ \\
\hline Total d & - & - & - & $65.4,0.18$ & $31.2,0.08$ & $143,0.38$ & - & - & - & - & $81.5,0.22$ & $27.6,0.07$ & - \\
\hline \multicolumn{14}{|c|}{ Energy $(\mathrm{kW} \cdot \mathrm{h})$} \\
\hline Mech vent e & 0.10 & 0.16 & 0.05 & 0.26 & 0 & 0.67 & 0.13 & 0.67 & 0.15 & 0.23 & 0.38 & 0 & 0.38 \\
\hline Total HVAC & 0.92 & 2.39 & 1.46 & 3.31 & 0.83 & 1.94 & 0.56 & 2.76 & 0.97 & 2.97 & 2.65 & 1.28 & 3.94 \\
\hline
\end{tabular}

Abbreviations: $\mathrm{C}_{\mathrm{in}}$, indoor formaldehyde concentration; $\mathrm{C}_{\text {out }}$, outdoor formaldehyde concentration; $\mathrm{T}_{\text {in }}$, indoor temperature; $\mathrm{T}_{\text {out }}$, outdoor temperature; $\mathrm{RH}_{\mathrm{in}}$, indoor relative humidity; $\mathrm{RH}_{\text {out }}$, outdoor relative humidity; mech vent, mechanical ventilation.

a. Air samples were analyzed following a modified version of EPA TO-11a.

b. Four-hour sample.

c. Measured with flow meter.

d. Measured with tracer gas test.

e. Energy consumed by the blower that was supplying outdoor air. 


\subsubsection{Session B}

Figures 4 through 6 and Table 6 indicate that indoor and outdoor temperatures were somewhat similar in Tests B1, B2 and B3, which allowed us to better evaluate the effects from the three mechanical ventilation schedules. The 24-hr average indoor and outdoor temperatures were about $75^{\circ} \mathrm{F}$ and $73^{\circ} \mathrm{F}$, respectively. The HVAC unit was able to adequately maintain the thermostat set point of $75^{\circ} \mathrm{F}$ given that the indoor temperature remained between 73 and $76^{\circ} \mathrm{F}$ in Session B. In Tests B2 and B3, average $R H_{\text {in }}$ values were higher while the mechanical ventilation was running (occupied hours $=58 \%$ vs. un-occupied hours $=53 \%$; non-peak utility hours $=52 \%$ vs. peak utility hours $=48 \%$ ) because outdoor air introduced water vapor indoors. The HVAC energy used in each of the three ventilation schedules were somewhat similar and ranged between 11.5 and $12.5 \mathrm{kWh}$.

Table 6 indicates that the desired mechanical ventilation rates were reasonably reached. Just as in Session A, infiltration was the highest when the mechanical ventilation was off: $13 \mathrm{cfm}(0.04$ $\left.\mathrm{h}^{-1}\right)$ during the un-occupied hours in Test B2, and $20 \mathrm{cfm}\left(0.05 \mathrm{~h}^{-1}\right)$ throughout the peak hours in Test B3.

Figure 4 indicates that continuous mechanical ventilation led to 1-hr formaldehyde concentrations ranging from 35 to $49 \mathrm{ppb}$ throughout the entire day, and with an average $C_{\text {in }}$ value during occupied hours of $48 \mathrm{ppb}$. During Test B2, Figure 5 shows how $C_{\text {in }}$ increased from 42 to $51 \mathrm{ppb}$ while no fresh air was being provided during the un-occupied hours. Subsequently, formaldehyde appears to have reached an approximate steady-state concentration of $40 \mathrm{ppb}$ in about two to three hours after mechanical ventilation was turned on. The average $C_{\text {in }}$ throughout the occupied hours was $42 \mathrm{ppb}$, or $88 \%$ of what was observed in Test B1. As illustrated in Figure $6, C_{\text {in }}$ built up from 40 to $54 \mathrm{ppb}$ in Test B3 while mechanical ventilation was not provided during the peak-demand hours. Thru the remaining part of the test, 1-hour samples dropped to about $41 \mathrm{ppb}$ with $82 \mathrm{cfm}$ of ventilation. The average $C_{i n}$ during the occupied hours was $51 \mathrm{ppb}$, which is 3 ppb higher than what was measured in Test B1. 


\section{Test B1}
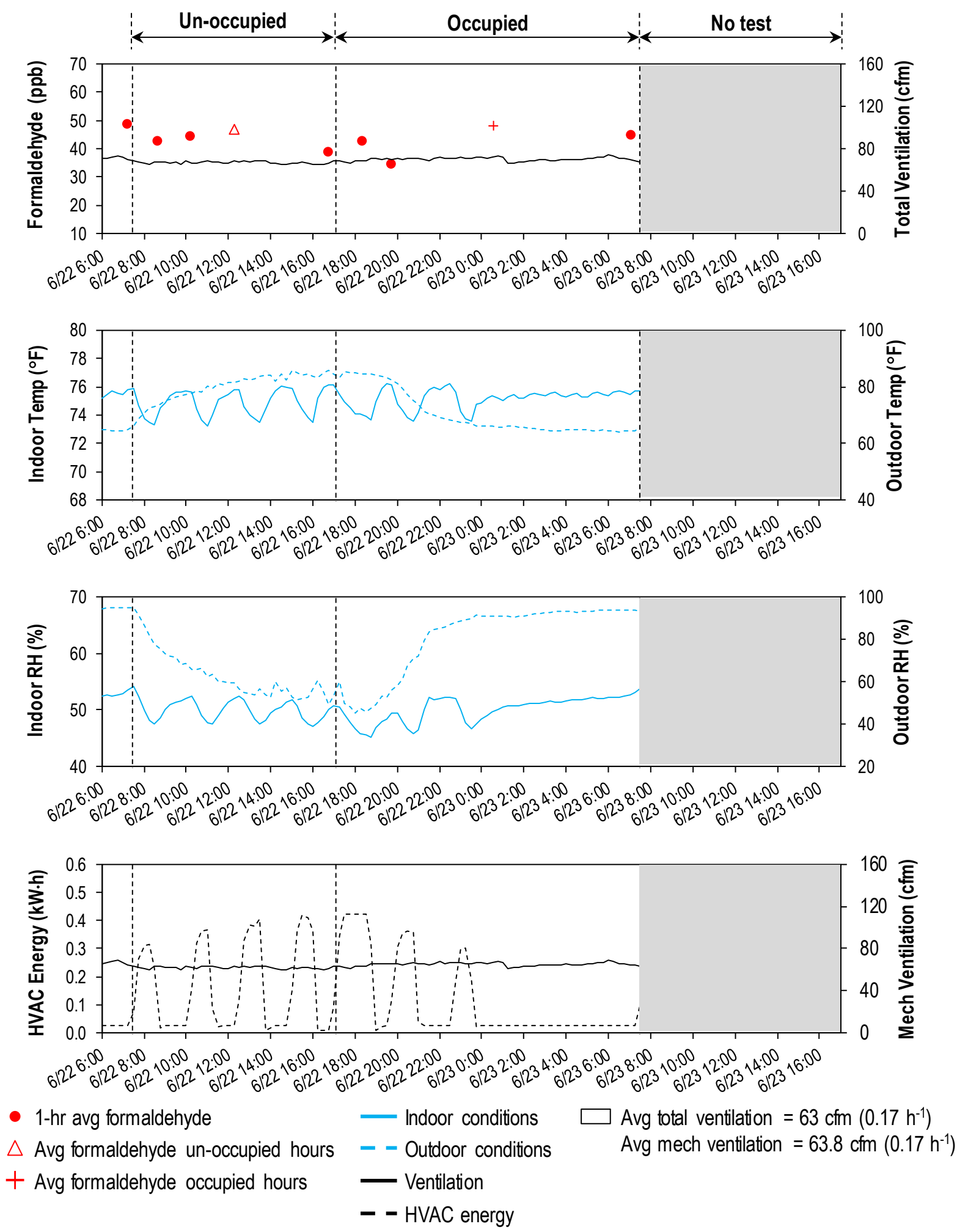

Figure 4. Formaldehyde concentrations, environmental conditions, and energy usage - Session B1. 
Test B2
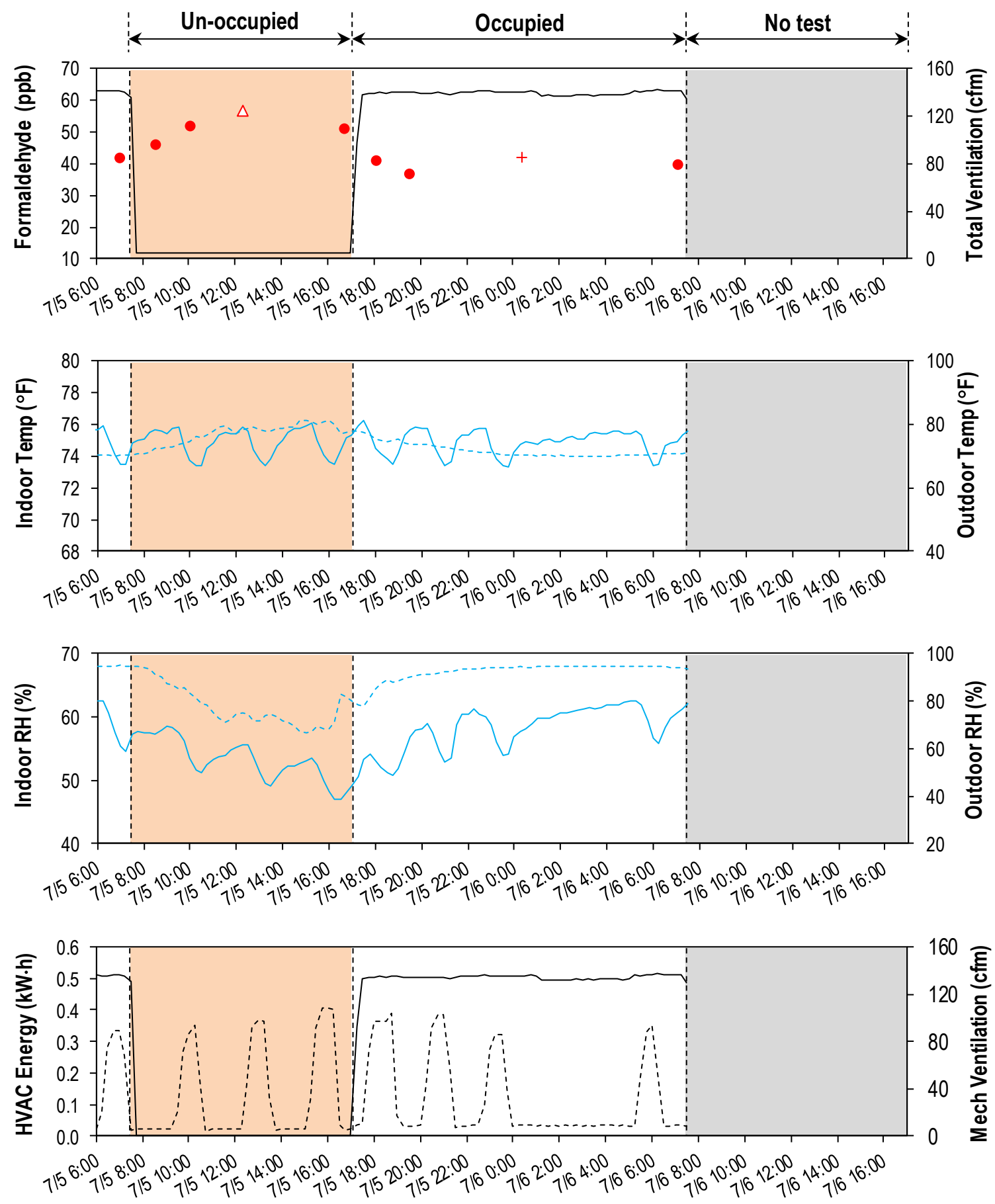

- 1-hr avg formaldehyde

$\triangle$ Avg formaldehyde un-occupied hours - - Outdoor conditions

+ Avg formaldehyde occupied hours $\longrightarrow$ Ventilation

- - HVAC energy
Avg total ventilation $=141 \mathrm{~cm}\left(0.38 \mathrm{~h}^{-1}\right)$

Avg mech ventilation $=134 \mathrm{~cm}\left(0.36 \mathrm{~h}^{-1}\right)$

Avg total ventilation $=13.2 \mathrm{~cm}\left(0.04 \mathrm{~h}^{-1}\right)$

Avg mech ventilation $=0 \mathrm{~cm}\left(0 \mathrm{~h}^{-1}\right)$

Figure 5. Formaldehyde concentrations, environmental conditions, and energy usage - Session B2. 
Test B3
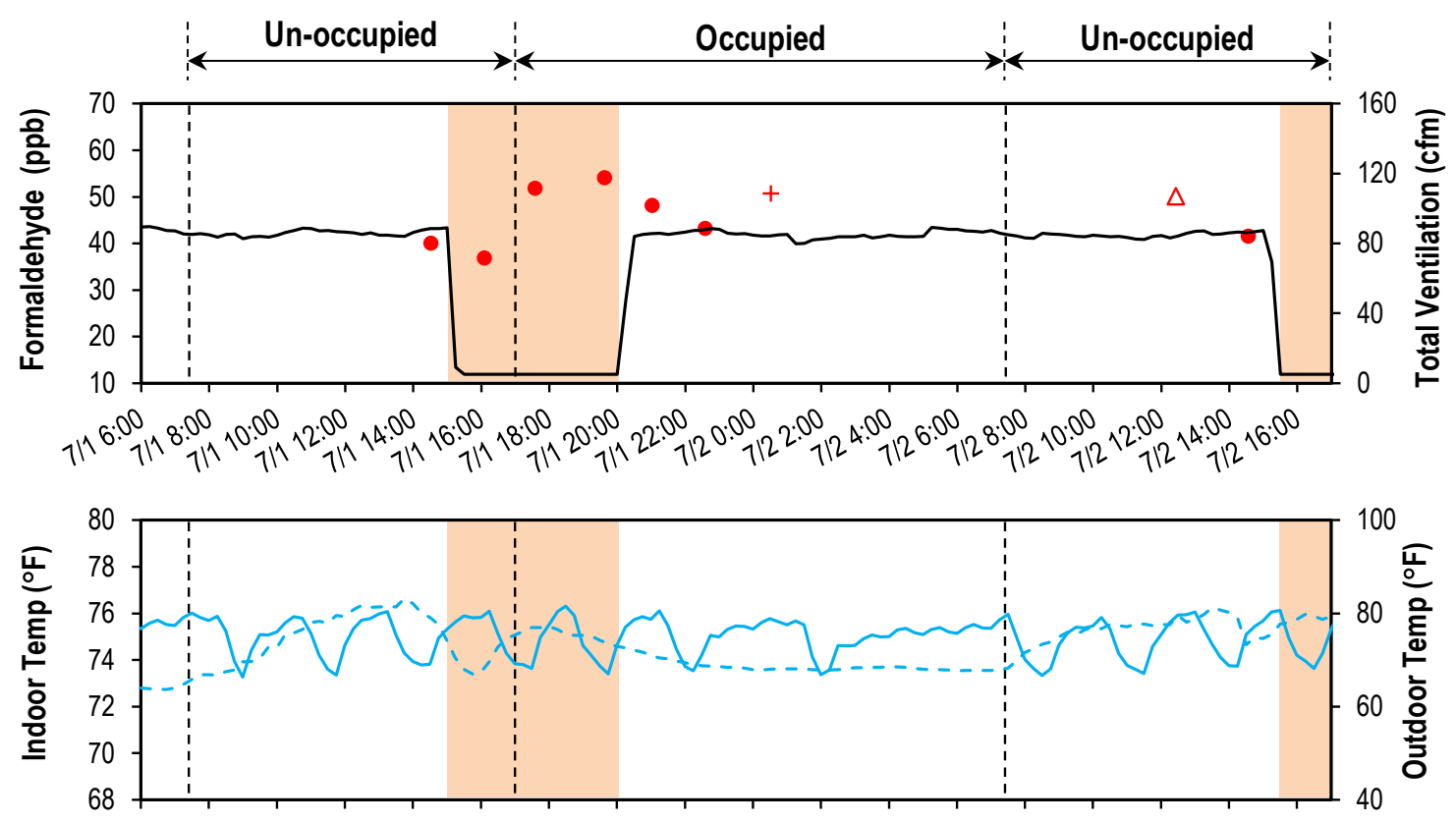

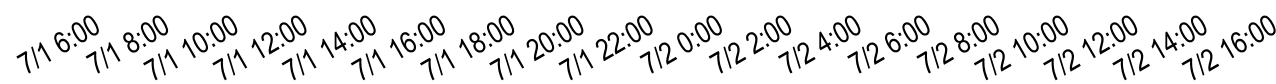

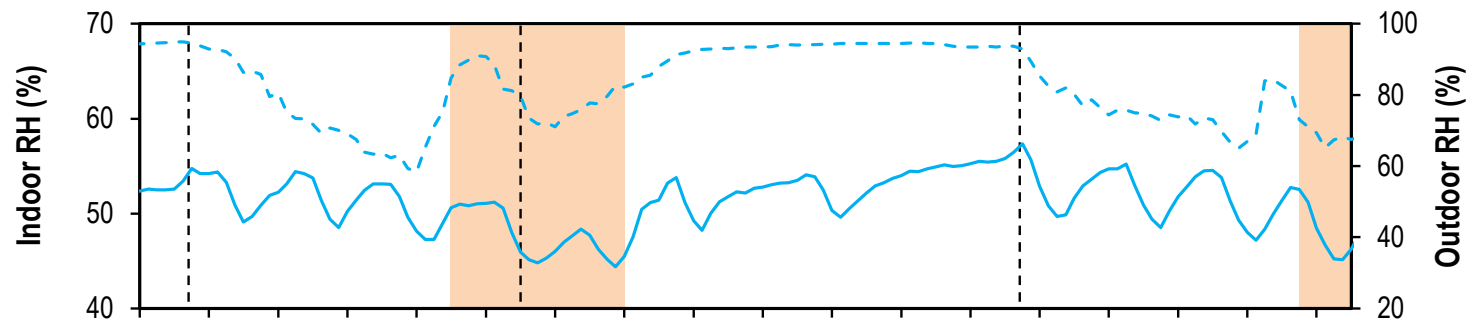

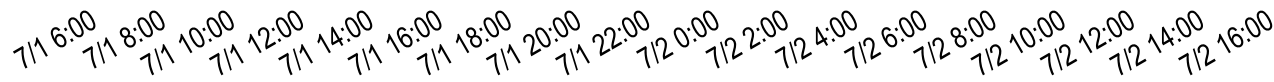

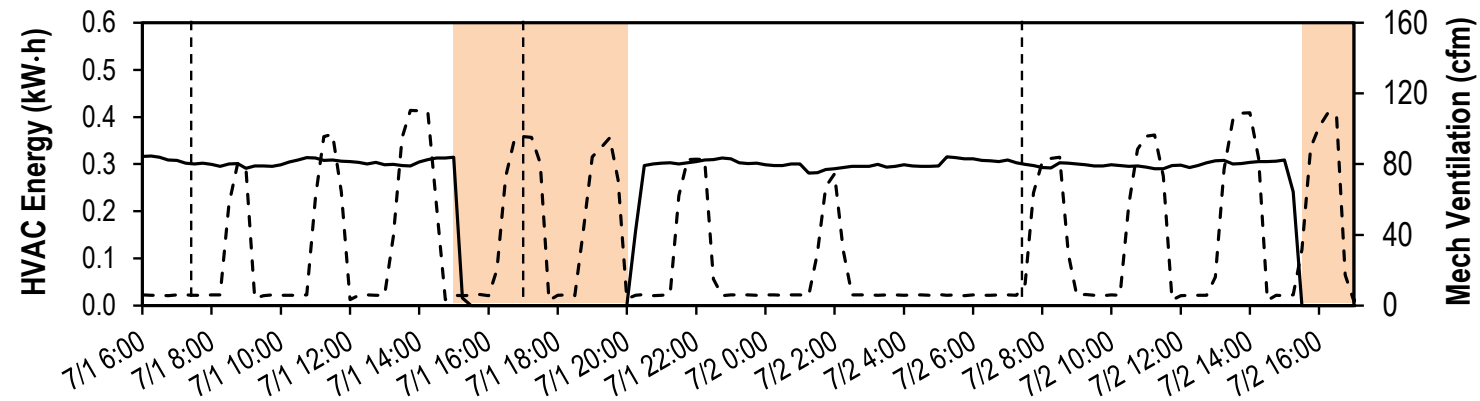

- 1-hr avg formaldehyde $\quad$ - Indoor conditions $\square$ Avg total ventilation $=82 \mathrm{~cm}\left(0.22 \mathrm{~h}^{-1}\right)$

$\triangle$ Avg formaldehyde un-occupied hours - - Outdoor conditions Avg mech ventilation $=78.4 \mathrm{~cm}\left(0.21 \mathrm{~h}^{-1}\right)$

+ Avg formaldehyde occupied hours

- Ventilation

$\square$ Avg total ventilation $=19.5 \mathrm{~cm}\left(0.05 \mathrm{~h}^{-1}\right)$

- - HVAC energy

Avg mech ventilation $=0 \mathrm{~cm}\left(0 \mathrm{~h}^{-1}\right)$

Figure 6. Formaldehyde concentrations, environmental conditions, and energy usage - Session B3. 
Table 6. Formaldehyde concentrations, environmental conditions, and energy usage during Session B.

\begin{tabular}{|c|c|c|c|c|c|c|c|c|c|c|c|c|c|}
\hline & \multicolumn{4}{|c|}{ Test B1: $6 / 22 / 13-6 / 23 / 13$} & \multicolumn{4}{|c|}{ Test B2: $7 / 5 / 13-7 / 6 / 13$} & \multicolumn{5}{|c|}{ Test B3: $7 / 1 / 13-7 / 2 / 13$} \\
\hline & Un-occupied & Occupied & Peak & 24-hr & Un-occupied & Occupied & Peak & 24-hr & Un-occupied & Occupied & Non-Peak & Peak & 24-hr \\
\hline \multicolumn{14}{|c|}{ Indoor and Outdoor Parameters } \\
\hline$C_{\text {in }}(p p b)$ & 47 & 48 & - & - & 57 & 42 & - & - & 50 & 51 & - & - & - \\
\hline $\mathrm{C}_{\text {out }}(\mathrm{ppb})$ & - & - & - & $4^{a}$ & - & - & - & b & - & - & - & - & $3^{a}$ \\
\hline $\mathrm{T}_{\text {in }}\left({ }^{\circ} \mathrm{F}\right)$ & $74.8 \pm 0.9$ & $75.2 \pm 0.7$ & $75 \pm 0.9$ & $75 \pm 0.7$ & $74.9 \pm 0.9$ & $74.9 \pm 0.8$ & $74.9 \pm 0.9$ & $74.9 \pm 0.8$ & $74.9 \pm 0.9$ & $75 \pm 0.7$ & $75 \pm 0.7$ & $75 \pm 1$ & $75 \pm 0.8$ \\
\hline $\mathrm{T}_{\text {out }}\left({ }^{\circ} \mathrm{F}\right)$ & $79.9 \pm 4.9$ & $70.7 \pm 7.7$ & $84.4 \pm 0.9$ & $74.3 \pm 8.1$ & $77 \pm 3$ & $71.7 \pm 2.1$ & $76.8 \pm 2.5$ & $73.8 \pm 3.6$ & $75.1 \pm 3.9$ & $70.2 \pm 3.1$ & $71.8 \pm 4.3$ & $73.6 \pm 3.2$ & $72.1 \pm 4.2$ \\
\hline $\mathrm{RH}_{\text {in }}(\%)$ & $49.9 \pm 1.8$ & $50.1 \pm 2.2$ & $48.3 \pm 1.8$ & $50 \pm 2.0$ & $53.0 \pm 3.2$ & $58.3 \pm 3.3$ & $52 \pm 3.2$ & $56.2 \pm 4.2$ & $51.7 \pm 2.4$ & $51.3 \pm 3.4$ & $52.4 \pm 2.4$ & $47.9 \pm 2.4$ & $51.5 \pm 3.1$ \\
\hline $\mathrm{RH}_{\text {out }}(\%)$ & $63.3 \pm 11.3$ & $80.3 \pm 17.1$ & $51.9 \pm 4.2$ & $73.6 \pm 17.2$ & $77.4 \pm 8.2$ & $92.3 \pm 3.8$ & $81.2 \pm 8.1$ & $86.4 \pm 9.4$ & $78.7 \pm 7.4$ & $89.2 \pm 7.5$ & $83.5 \pm 10.6$ & $80.3 \pm 6.5$ & $85.0 \pm 9.1$ \\
\hline \multicolumn{14}{|c|}{ Ventilation Rates $\left(\mathrm{cfm}, \mathrm{h}^{-1}\right)$} \\
\hline Mechanical c & $61.9,0.17$ & $65.0,0.17$ & - & $63.8,0.17$ & 0 & $134,0.36$ & - & $80.6,0.22$ & $66.4,0.18$ & $61.5,0.16$ & $78.4,0.21$ & 0 & $63.4,0.17$ \\
\hline Total d & - & - & - & $63,0.17$ & $13.2,0.04$ & $141,0.38$ & - & - & - & - & $82,0.22$ & $19.5,0.05$ & - \\
\hline \multicolumn{14}{|c|}{ Energy $(\mathrm{kW} \cdot \mathrm{h})$} \\
\hline Mech vent $\mathrm{e}$ & 0.10 & 0.16 & 0.05 & 0.26 & 0 & 0.67 & 0.13 & 0.67 & 0.15 & 0.23 & 0.38 & 0 & 0.38 \\
\hline Total HVAC & 6.17 & 6.34 & 4.78 & 12.5 & 4.72 & 6.79 & 3.76 & 11.5 & 5.96 & 5.54 & 8.16 & 3.34 & 11.5 \\
\hline
\end{tabular}

Abbreviations: $\mathrm{C}_{\text {in }}$, indoor formaldehyde concentration; $\mathrm{C}_{\text {out }}$, outdoor formaldehyde concentration; $\mathrm{T}_{\text {in }}$, indoor temperature; $\mathrm{T}_{\text {out }}$, outdoor temperature; $\mathrm{RH}_{\mathrm{in}}$, indoor relative humidity; $\mathrm{RH}_{\text {out }}$, outdoor relative humidity; mech vent, mechanical ventilation.
a. Four-hour sample.
b. Sorbent congealed because of high ambient moisture levels.
c. Measured with flow meter.
d. Measured with tracer gas test.
e. Energy consumed by the blower that was supplying outdoor air. 


\subsubsection{Session C}

Figures 7 to 9 and Table 7 show that indoor and outdoor temperatures were somewhat similar throughout Tests $\mathrm{C} 1, \mathrm{C} 2$ and C3. Indoor temperature averaged $75^{\circ} \mathrm{F}$ in 24 hours, and fluctuated between 73 and $76^{\circ} \mathrm{F}$. The 24 -hr average outdoor temperature was also $75^{\circ} \mathrm{F}$. Outdoor relative humidity varied among tests: the 24-hr average $R H_{\text {out }}$ was in Test $\mathrm{C} 2$ was $67 \%$; however, because of rain this number was $88 \%$ in Test $\mathrm{C} 1$ and $79 \%$ in Test $\mathrm{C} 3$. These outdoor conditions were not reflected indoors because of dehumidification through the HVAC unit; $R H_{\text {in }}$ was $52 \%$ in Test $\mathrm{C} 2$, and $53 \%$ in the other two evaluations.

In Test $\mathrm{C} 1$, the average $C_{\text {in }}$ during occupied hours was $51 \mathrm{ppb}$, and the 1-hr samples throughout this period varied between 42 and $49 \mathrm{ppb}$. Figure 8 illustrates how formaldehyde increased in Test $\mathrm{C} 2$ from 34 to about $50 \mathrm{ppb}$ while mechanical ventilation was off during the unoccupied hours. After ventilation was turned on, a steady-state concentration of $36 \mathrm{ppb}$ was reached in approximately two to three hours. The average formaldehyde concentration during the occupied hours in Test C2 was 37 ppb, or $27 \%$ lower than what observed with continuous ventilation. In Test C3, formaldehyde climbed from 40 to about $50 \mathrm{ppb}$ during the unventilated peak-demand hours. Concentrations diminished to approximately $40 \mathrm{ppb}$ three hours after mechanical ventilation was resumed. The average formaldehyde concentration during the occupied hours was $47 \mathrm{ppb}$, which is $4 \mathrm{ppb}$ lower than the corresponding measurement from Test $\mathrm{C} 1$.

\subsubsection{Summary of Field Measurements}

Figures 10 through 12 summarize the data from all the tests: indoor and outdoor temperature and relative humidity, HVAC energy used, and formaldehyde concentrations. These data do not show clear HVAC energy demand patterns among the three mechanical ventilation schedules primarily because changes in $T_{\text {out }}$ and $R H_{\text {out }}$ influenced energy usage. Simulation results that will be presented in later sections provide better insight on the energy-related effects from the ventilation schedules. With regard to formaldehyde, Figures 11 shows that concentrations during the occupancy-based ventilation schedule were 73 to $88 \%$ lower than those obtained with the utility-based and continuous ventilation schedules. In contrast, Figure 12 indicates that during the un-occupied hours $C_{\text {in }}$ was 12 to $30 \%$ higher throughout the occupancy-based schedule than during the other two ventilation schemes. 


\section{Test C1}
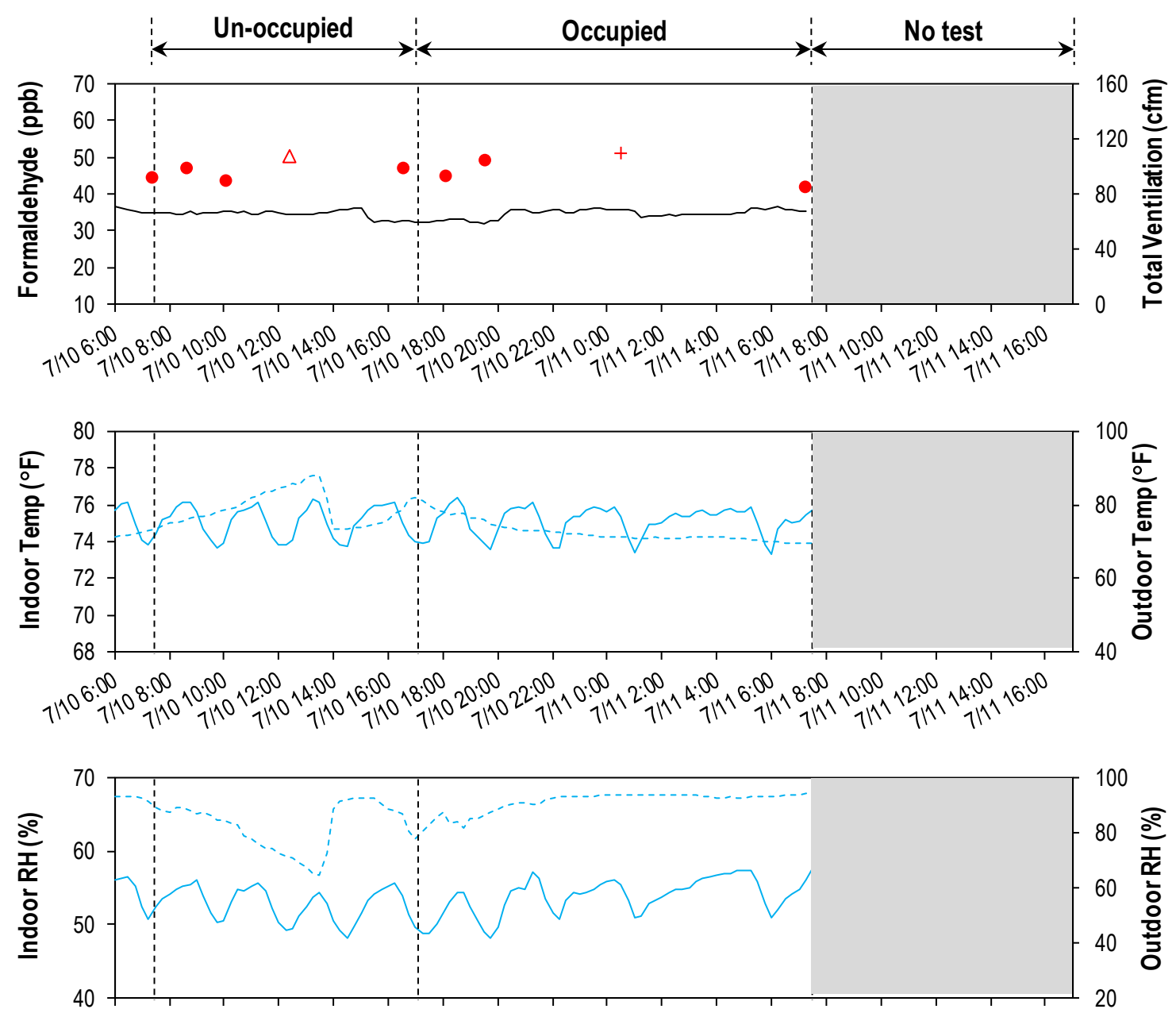

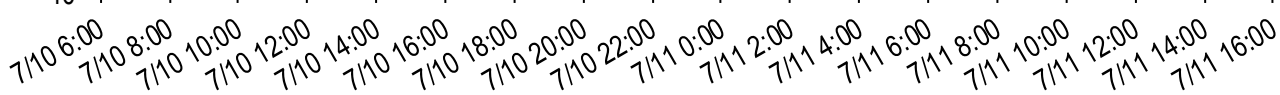
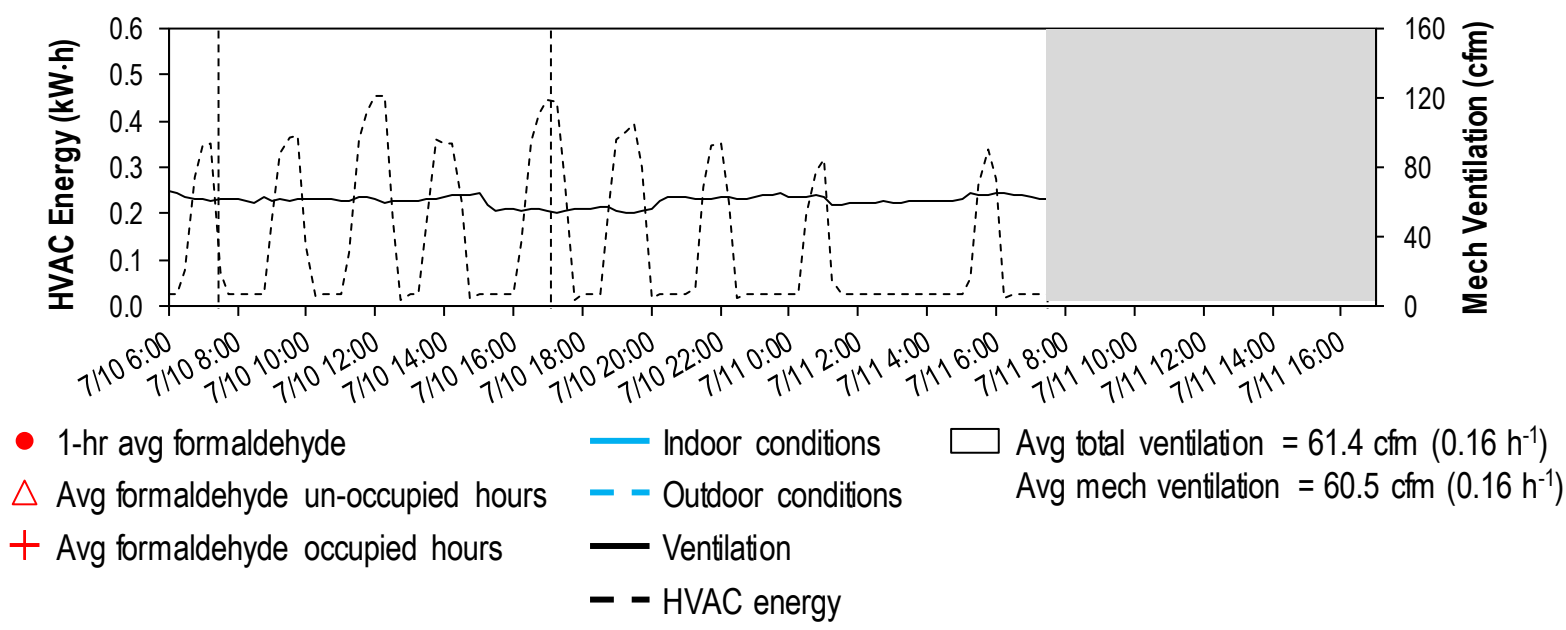

Figure 7. Formaldehyde concentrations, environmental conditions, and energy usage - Session C1. 
Test C2
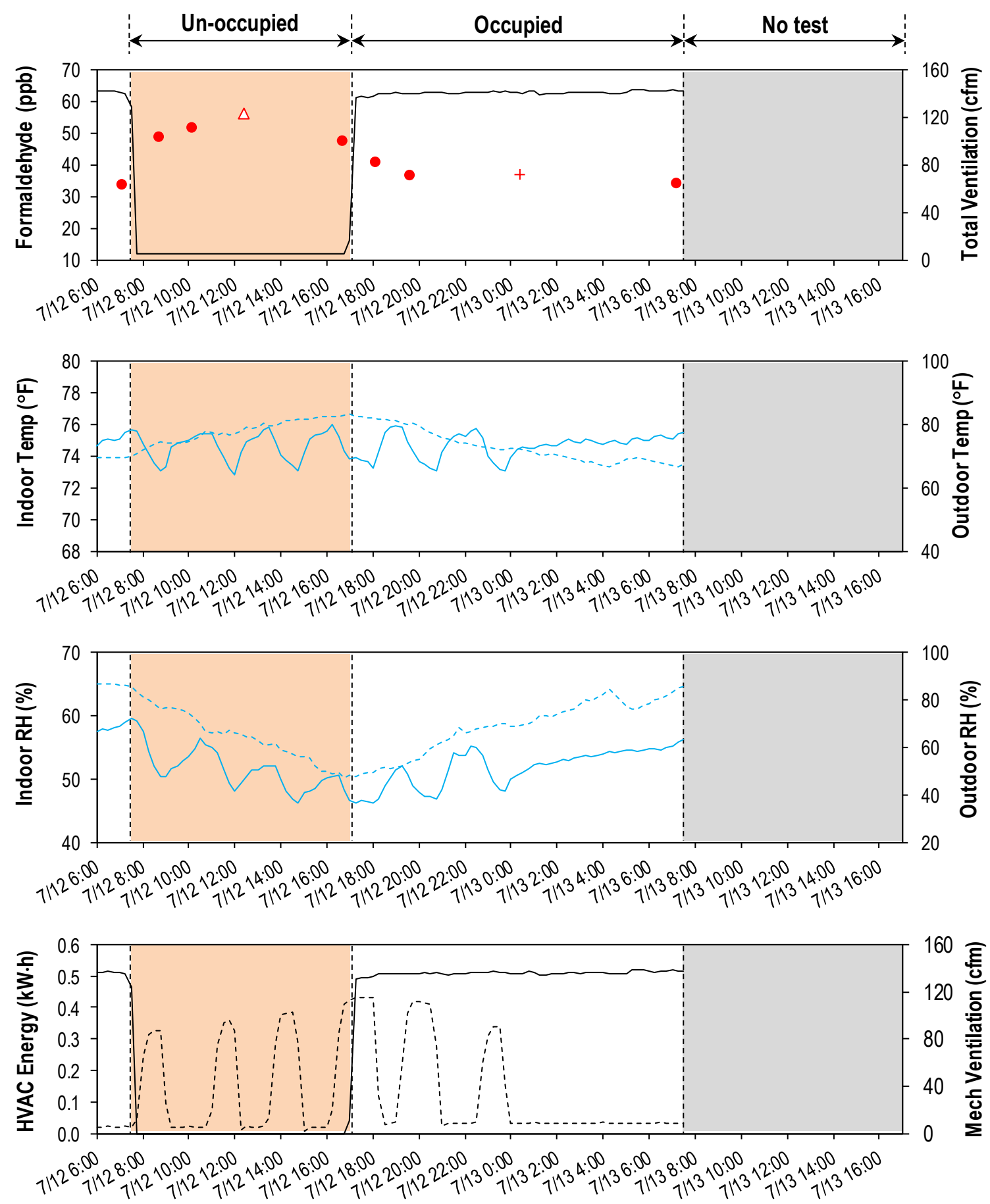

- 1-hr avg formaldehyde

$\triangle$ Avg formaldehyde un-occupied hours - - Outdoor conditions

+ Avg formaldehyde occupied hours - Ventilation - - HVAC energy $\square$ Avg total ventilation $=143 \mathrm{cfm}\left(0.38 \mathrm{~h}^{-1}\right)$

Avg mech ventilation $=136 \mathrm{~cm}\left(0.36 \mathrm{~h}^{-1}\right)$

Avg total ventilation $=17.6 \mathrm{~cm}\left(0.05 \mathrm{~h}^{-1}\right)$

Avg mech ventilation $=0 \mathrm{~cm}\left(0 \mathrm{~h}^{-1}\right)$

Figure 8. Formaldehyde concentrations, environmental conditions, and energy usage - Session C2. 
Test C3
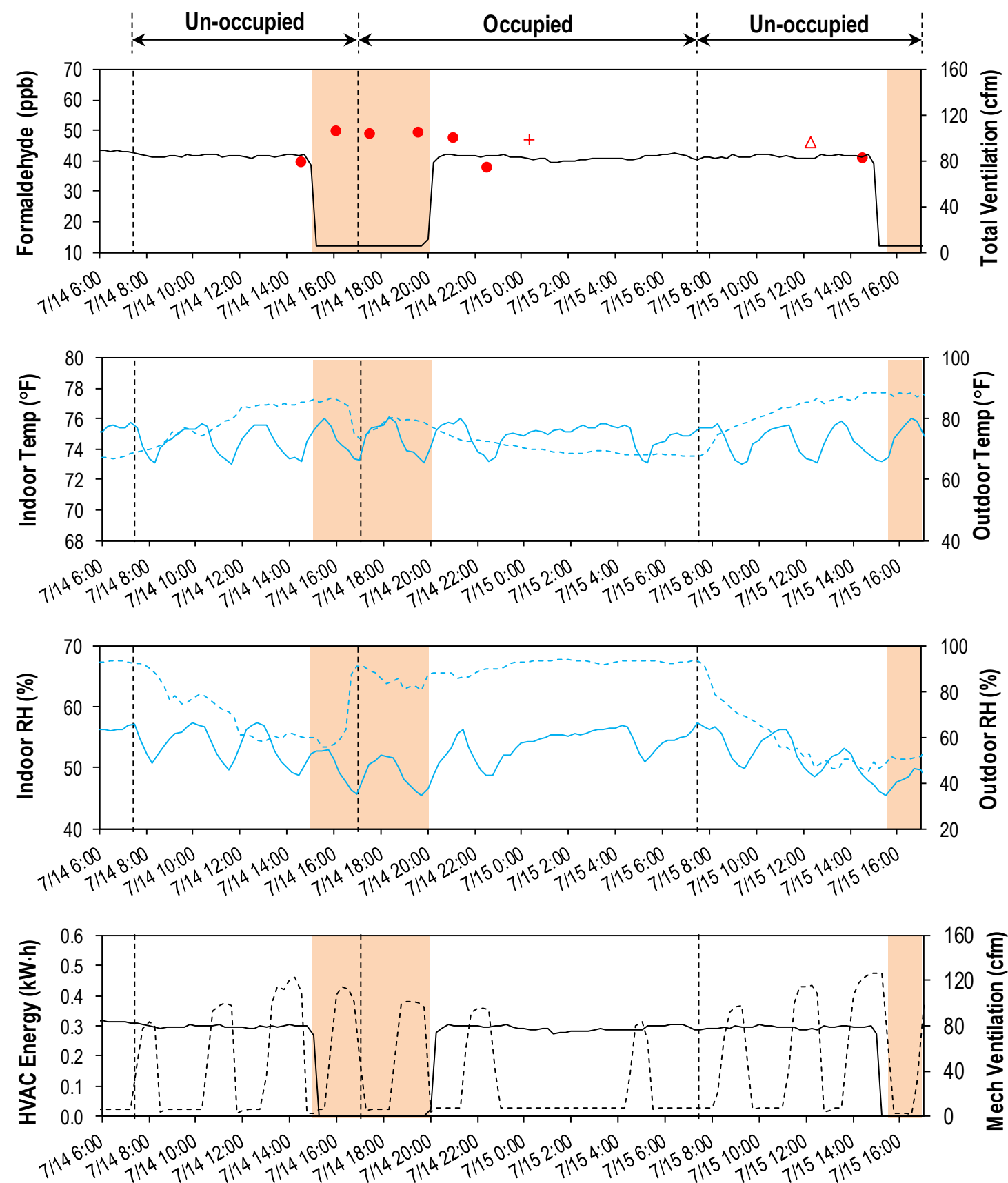
- 1-hr avg formaldehyde
- Indoor conditions
Avg total ventilation $=82.2 \mathrm{~cm}\left(0.22 \mathrm{~h}^{-1}\right)$
$\triangle$ Avg formaldehyde un-occupied hours -- Outdoor conditions Avg mech ventilation $=77.3 \mathrm{~cm}\left(0.21 \mathrm{~h}^{-1}\right)$
+ Avg formaldehyde occupied hours
- Ventilation
Avg total ventilation $=9.4 \mathrm{~cm}\left(0.02 \mathrm{~h}^{-1}\right)$
- - HVAC energy
Avg mech ventilation $=0.3 \mathrm{~cm}\left(0.001 \mathrm{~h}^{-1}\right)$

Figure 9. Formaldehyde concentrations, environmental conditions, and energy usage - Session C3. 
Table 7. Formaldehyde concentrations, environmental conditions, and energy usage during Session C.

\begin{tabular}{|c|c|c|c|c|c|c|c|c|c|c|c|c|c|}
\hline & \multicolumn{4}{|c|}{ Test C1: $7 / 10 / 13-7 / 11 / 13$} & \multicolumn{4}{|c|}{ Test C2: $7 / 12 / 13-7 / 13 / 13$} & \multicolumn{5}{|c|}{ Test C3: $7 / 14 / 13-7 / 15 / 13$} \\
\hline & Un-occupied & Occupied & Peak & 24-hr & Un-occupied & Occupied & Peak & 24-hr & Un-occupied & Occupied & Non-Peak & Peak & 24-hr \\
\hline \multicolumn{14}{|c|}{ Indoor and Outdoor Parameters } \\
\hline$C_{\text {in }}(p p b)$ & 50 & 51 & - & - & 56 & 37 & - & - & 46 & 47 & - & - & - \\
\hline $\mathrm{C}_{\text {out }}(\mathrm{ppb})$ & - & - & - & $b$ & - & - & - & $3^{a}$ & - & - & - & - & $4^{a}$ \\
\hline $\mathrm{T}_{\text {in }}\left({ }^{\circ} \mathrm{F}\right)$ & $75.1 \pm 0.8$ & $75.1 \pm 0.8$ & $75.1 \pm 0.9$ & $75.1 \pm 0.8$ & $74.6 \pm 0.9$ & $74.7 \pm 0.7$ & $74.8 \pm 0.9$ & $74.6 \pm 0.8$ & $74.6 \pm 0.9$ & $74.9 \pm 0.8$ & $74.8 \pm 0.9$ & $74.7 \pm 1$ & $74.8 \pm 0.9$ \\
\hline $\mathrm{T}_{\text {out }}\left({ }^{\circ} \mathrm{F}\right)$ & $79 \pm 4.6$ & $72.8 \pm 3$ & $77.4 \pm 2.3$ & $75.2 \pm 4.8$ & $78.1 \pm 3.5$ & $72.9 \pm 5$ & $81.7 \pm 1$ & $75 \pm 5.2$ & $82.3 \pm 5.3$ & $71.9 \pm 4$ & $74.8 \pm 6.8$ & $80.6 \pm 4.1$ & $76.1 \pm 6.8$ \\
\hline $\mathrm{RH}_{\text {in }}(\%)$ & $52.9 \pm 2.2$ & $53.7 \pm 2.5$ & $52 \pm 2.3$ & $53.4 \pm 2.4$ & $50.9 \pm 2.8$ & $52 \pm 2.9$ & $48.7 \pm 1.8$ & $51.6 \pm 2.9$ & $52.3 \pm 2.9$ & $52.8 \pm 3.1$ & $53.3 \pm 2.7$ & $49.7 \pm 2.6$ & $52.6 \pm 3$ \\
\hline $\mathrm{RH}_{\text {out }}(\%)$ & $82.6 \pm 8.5$ & $91 \pm 3.9$ & $86 \pm 4.1$ & $87.7 \pm 7.4$ & $64.3 \pm 10.2$ & $68.8 \pm 11.1$ & $50.7 \pm 2.4$ & $67 \pm 11$ & $61.6 \pm 13.1$ & $90.5 \pm 3.7$ & $76.4 \pm 17.3$ & $76.3 \pm 13.2$ & $79 \pm 16.6$ \\
\hline \multicolumn{14}{|c|}{ Ventilation Rates (cfm, $\mathrm{h}^{-1}$ ) } \\
\hline Mechanical c & $60.6 \pm 2.6$ & $60.5 \pm 3.4$ & - & $60.5,0.16$ & 0 & $136,0.36$ & - & $82.1, \quad 0.22$ & $64.1,0.17$ & $60.6,0.16$ & $77.3,0.21$ & 0 & $62.5,0.17$ \\
\hline Total d & - & - & - & $61.4,0.16$ & $17.6,0.05$ & $143,0.38$ & - & - & - & - & $82.2,0.22$ & $9.4,0.02$ & - \\
\hline \multicolumn{14}{|c|}{ Energy (kW·h) } \\
\hline Mech vent e & 0.10 & 0.16 & 0.05 & 0.26 & 0 & 0.67 & 0.13 & 0.67 & 0.15 & 0.23 & 0.38 & 0 & 0.38 \\
\hline HVAC & 6.2 & 6.7 & 3.9 & 12.9 & 6.07 & 7.10 & 4.28 & 13.2 & 8.07 & 6.12 & 9.87 & 4.32 & 14.2 \\
\hline
\end{tabular}

Abbreviations: $\mathrm{C}_{\mathrm{in}}$, indoor formaldehyde concentration; $\mathrm{C}_{\text {out }}$, outdoor formaldehyde concentration; $\mathrm{T}_{\text {in }}$, indoor temperature; $\mathrm{T}_{\text {out }}$, outdoor temperature; $\mathrm{RH}_{\mathrm{in}}$, indoor relative humidity; $\mathrm{RH}_{\text {out }}$, outdoor relative humidity; mech vent, mechanical ventilation.
a. Four-hour sample.
b. Sorbent congealed because of high ambient moisture levels.
c. Measured with flow meter.
d. Measured with tracer gas test.
e. Energy consumed by the blower that was supplying outdoor air. 

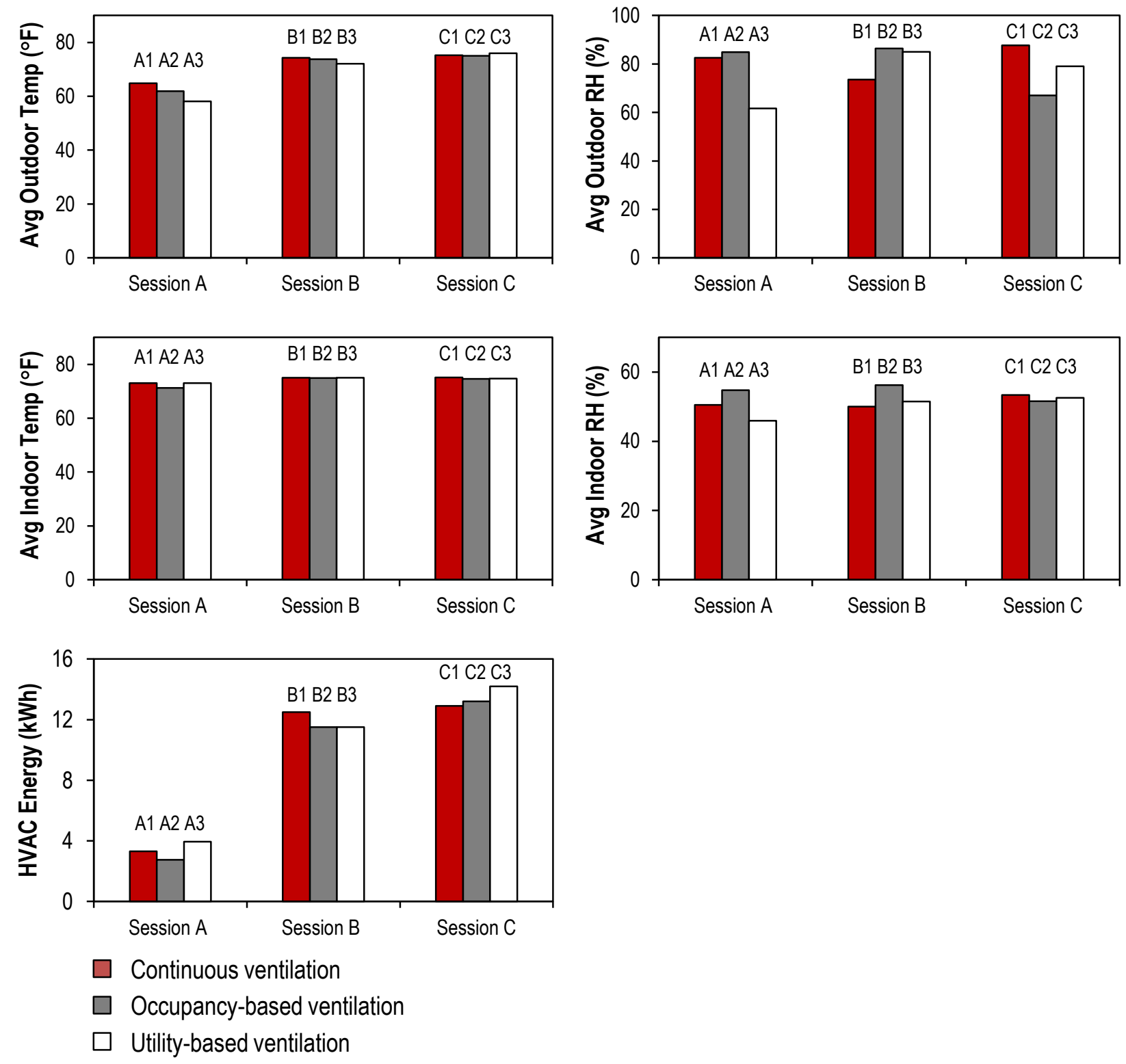

Figure 10. Measurements collected during the 24-hour test. 

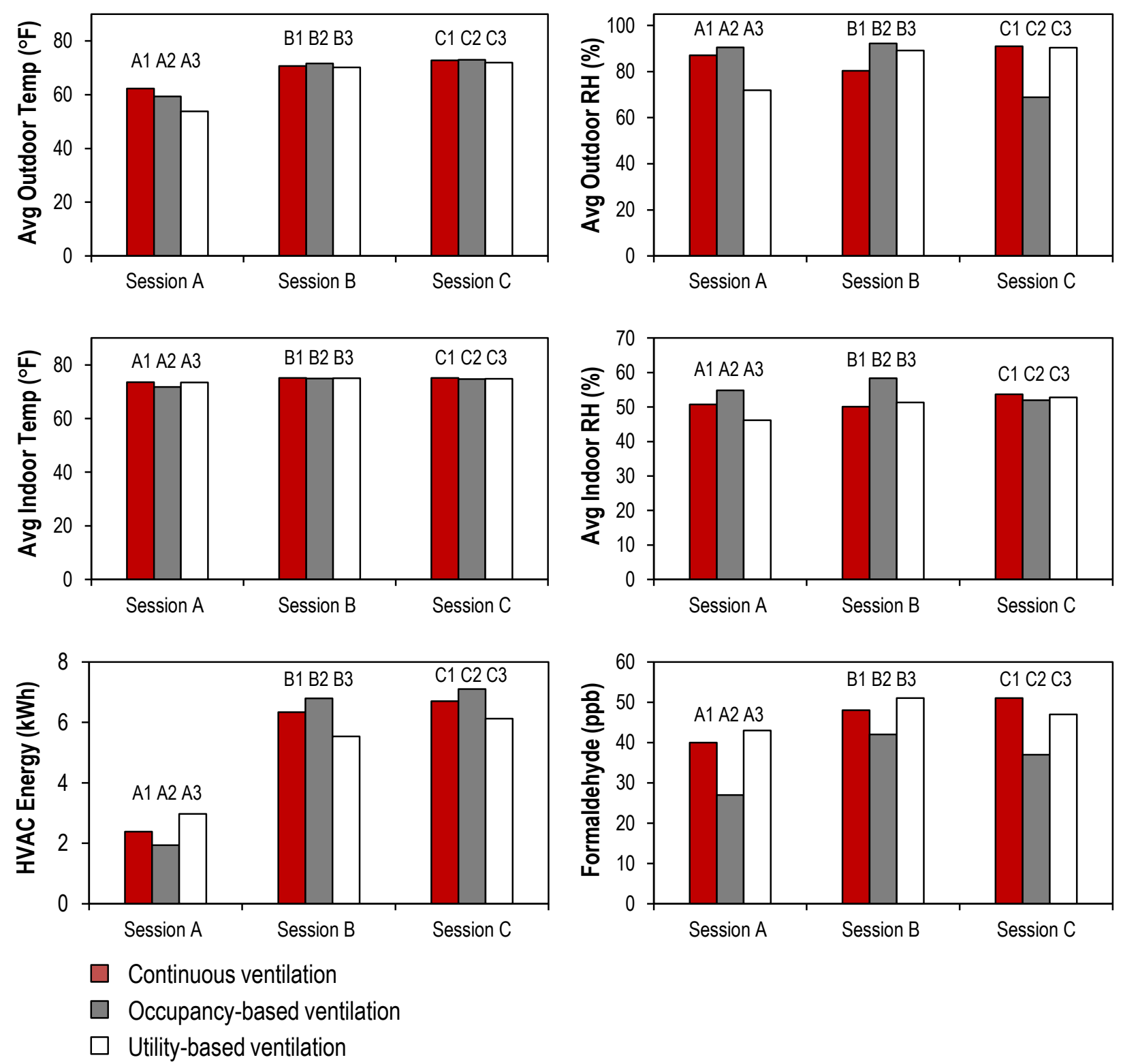

Figure 11. Measurements during occupied hours (5:00 pm to 7:30 am).

a. Test A1: Formaldehyde concentration was copied from the 24-hr measurement.

b. Test A2: Formaldehyde concentration was estimated as the area under the 1-hr measurements. 

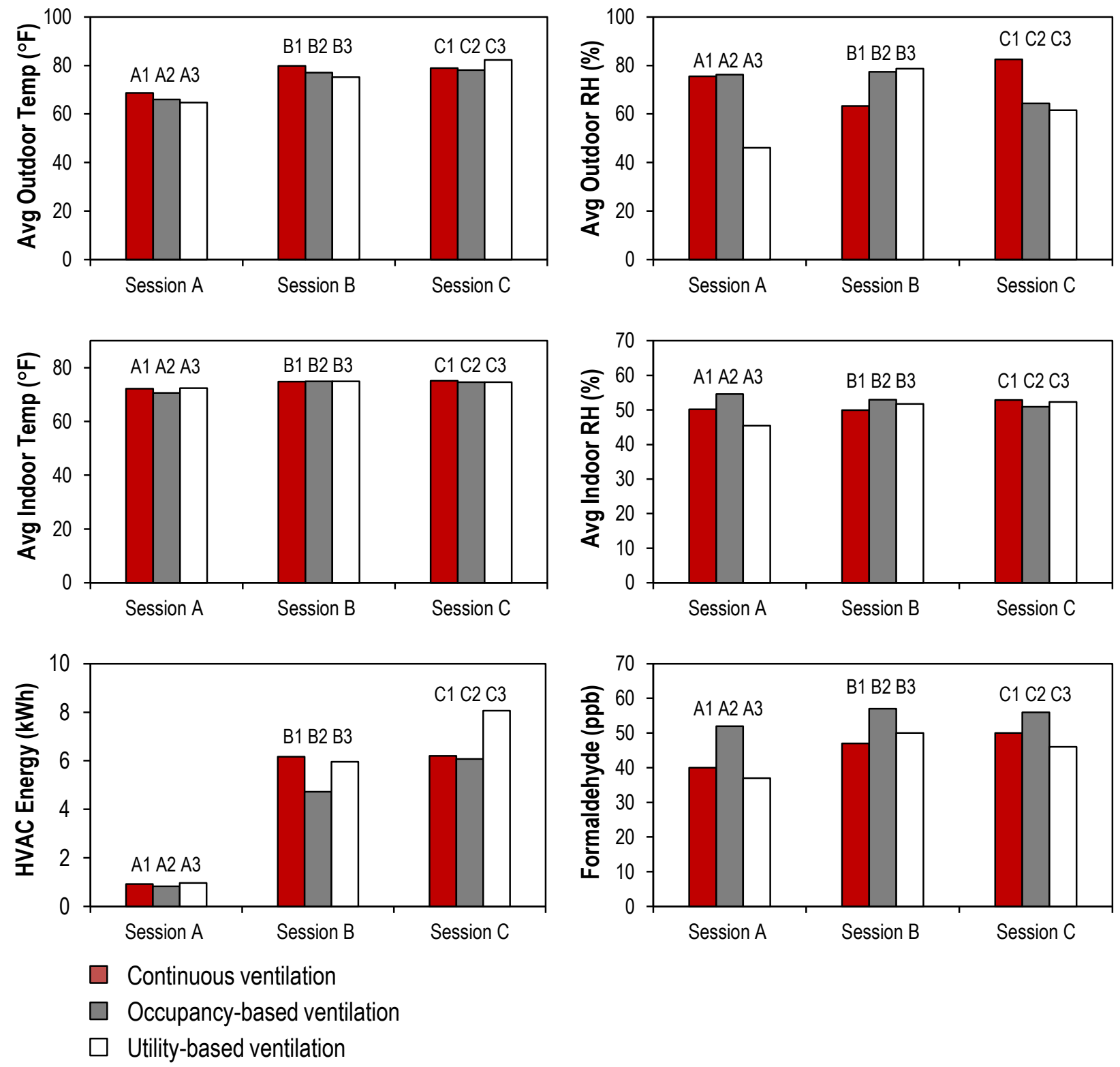

Figure 12. Measurements during un-occupied hours (7:30 am to 5:00 pm).

a. Test A1: Formaldehyde concentration was copied from the 24-hr measurement.

b. Test A2: Formaldehyde concentration was estimated as the area under the 1-hr measurements. 


\subsection{Formaldehyde Sources}

We collected 24-hr air samples from various locations in the test house to gather insight on potential sources of formaldehyde. The areas we sampled were the attached garage, attic, cavity of exterior wall, cavity of interior wall, and the dining area served as the baseline. Most of these locations were sampled in the spring (3/13/13) and summer (7/8/13). Although the air flow meter measured a mechanical ventilation rate of $\sim 40 \mathrm{cfm}\left(0.11 \mathrm{~h}^{-1}\right)$, tracer gas results indicate that the total ventilation was significantly higher in the spring evaluation $\left(100 \mathrm{cfm}, 0.27 \mathrm{~h}^{-1}\right)$ than in the summer $\left(52 \mathrm{cfm}, 0.14 \mathrm{~h}^{-1}\right)$ because of windy conditions of up to $14 \mathrm{miles} / \mathrm{h}$. Figure 13 illustrates the seasonal increase in concentration. Moreover, this figure suggests that the garage and attic were not sources of indoor formaldehyde given that their concentrations were lower than $C_{i n}$. However, concentrations in the wall cavities were higher than indoors. In the spring, formaldehyde in the exterior wall cavity was $30 \mathrm{ppb}$, while $C_{\text {in }}$ was $26 \mathrm{ppb}$. This discrepancy was much higher in the summer: concentrations in the exterior and interior wall cavities were 101 and $107 \mathrm{ppb}$, respectively, while $C_{i n}$ was $58 \mathrm{ppb}$. These results imply that the drywall could have been acting as a secondary source of formaldehyde given that it is a material that is common to interior and exterior walls. Liu et al. (2009) and Matthews et al. (1987) evaluated drywall as a storage material for formaldehyde that can serve as a secondary source in homes.

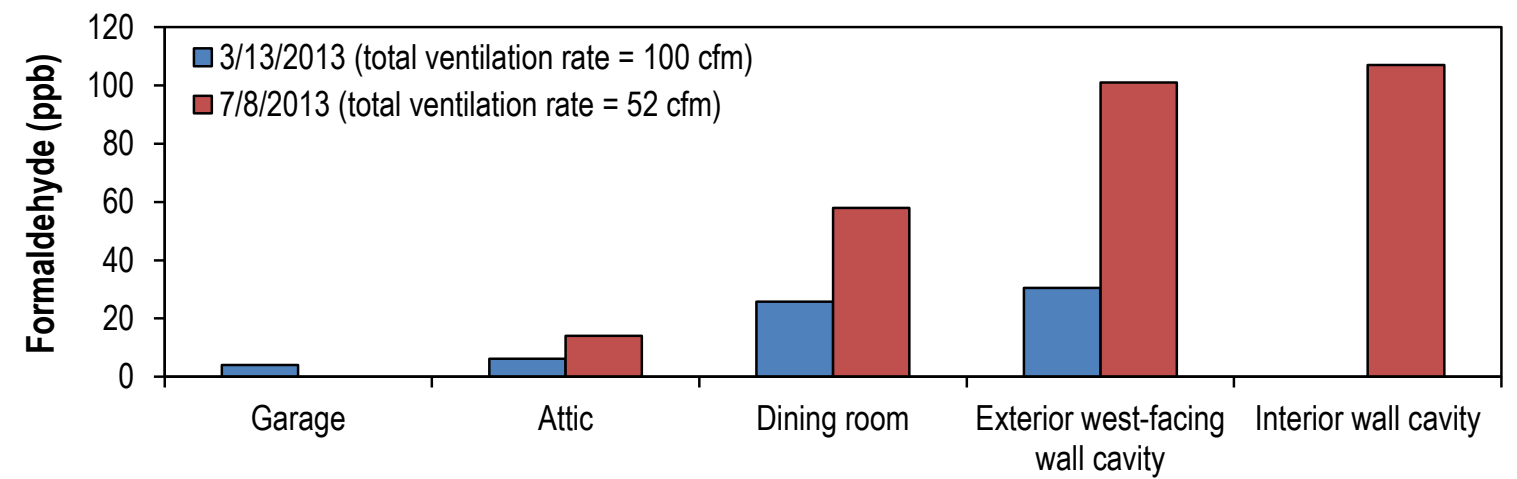

Figure 13. Formaldehyde concentrations collected in March and July 2013 from various locations within and adjacent to the living area.

\subsection{Simulations}

\subsubsection{Multivariate Regressions}

We conducted multivariate regressions to evaluate the effect of indoor temperature and total ventilation on formaldehyde concentrations. The derived equation for hourly formaldehyde concentrations is:

$$
C_{\text {in }}=-44.8 A E R+5.83 T_{\text {in }}-1679.8 \quad(p<0.001) \quad[1]
$$

where AER is the total air exchange or ventilation rate, and the units for $C_{i n}$, AER and $T_{i n}$ are $\mathrm{ppb}, \mathrm{h}^{-1}$ and Kelvin, respectively. Both AER and $T_{\text {in }}$ are statistically significant predictors of formaldehyde concentrations ( $p<0.001$ ) at the evaluated indoor conditions: $68.8^{\circ} \mathrm{F} \leq T_{\text {in }} \leq 75.6$ ${ }^{\circ} \mathrm{F}, 0.04 \mathrm{~h}^{-1} \leq \mathrm{AER} \leq 0.39 \mathrm{~h}^{-1}(13.2 \mathrm{cfm} \leq \mathrm{AER} \leq 145 \mathrm{cfm})$. Figure 14 illustrates good correlation between the estimated and measured formaldehyde concentrations $\left(\mathrm{R}^{2}=0.8\right)$. The 
observed linear relationship between $C_{i n}$ and $T_{\text {in }}$ is in agreement with the Berge model (Berge et al. 1980), which predicts a close to linear association between formaldehyde concentrations and temperature at a given relative humidity and at the temperature range that was evaluated in this study. Similarly, Equation 1 indicates a linear relationship between $C_{i n}$ and AER for the range of air exchange rates that were assessed in the present research. The Hoetjer-Berge-Fujii equation for steady-state formaldehyde concentrations (Myers 1984) supports a near linear dependence of $C_{i n}$ on ventilation when it varies between 0.04 and $0.39 \mathrm{~h}^{-1}$. Moreover, Willem et al. (2013) also noted this trend after monitoring these two variables in new US homes when air exchange rates were lower than $0.6 \mathrm{~h}^{-1}$. Although informative, these results should be interpreted with caution because we derived them with data from a single house that was four years old. The enclosure of this test facility is more energy efficient than what is found in the US housing stock, but it is consistent with the 2012 International Residential Code (IRC) requirements for a new home. Furthermore, average formaldehyde concentrations in this test house were in the top $25^{\text {th }}$ percentile of the measurements that Offermann (2009) observed in California homes that were less than six years old.

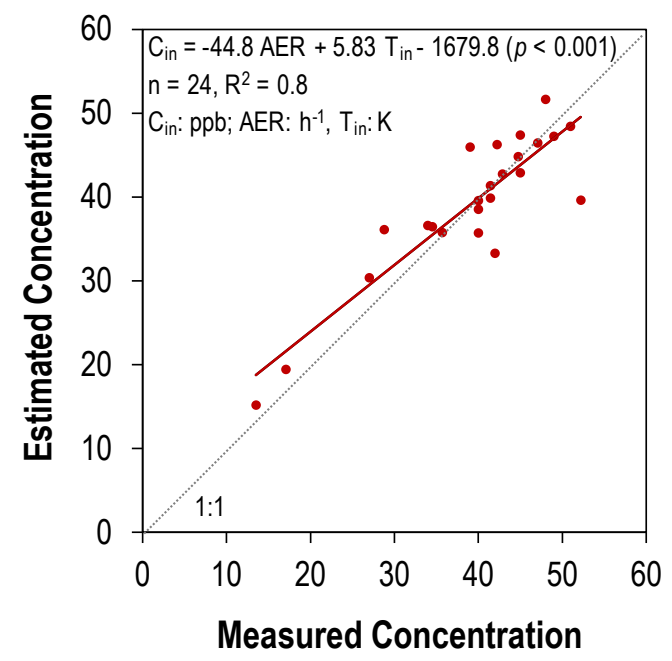

Figure 14. Measured and estimated formaldehyde concentrations.

\subsubsection{EnergyPlus Models}

We incorporated Equation 1 into an EnergyPlus model to evaluate the effect of the three mechanical ventilation schedules listed in Table 8 on formaldehyde concentrations and energy. This was done by running EnergyPlus without mechanical ventilation to get infiltration rates for each hour of the year. Hourly total ventilation was then estimated as the root sum square of the mechanical ventilation and infiltration. Formaldehyde emission rates for each hour were obtained by multiplying total ventilation times the concentration estimated per Equation 1. The last step was to incorporate the formaldehyde emission rates into the final EneryPlus run.

The intermittent ventilation schedules were applied from Monday through Friday; continuous ventilation was used on weekends because occupancy hours are more variable. As Table 8 indicates, the ventilation hours in the occupancy-based schedule ended at 8:00 am, although during the field experiments we turned off the mechanical ventilation at 7:30 am, because it was less cumbersome to model and obtain results from EnergyPlus using whole hours. Moreover, 
Table 9 shows one of the time-of-use electricity rates that TVA has been considering. With these in mind, we divided the utility-based schedule into summer (May - October) and nonsummer (November - April) months. Note that the hours in which the mechanical ventilation was shut down in the utility-based schedule do not span the entire peak demand period in Table 9 because we were aiming to simultaneously optimize IAQ and peak energy use. Major assumptions in the EnergyPlus model include:

a. Well-mixed indoor environment

b. Outdoor formaldehyde concentration $=2 \mathrm{ppb}$

c. No formaldehyde sinks

d. Formaldehyde concentrations reach its new value right after ventilation rates or indoor temperatures change per Equation 1. Therefore, estimated concentrations immediately after ventilation is turned on are lower than expected, and concentrations right after ventilation is shut down are higher than expected. Given that the field data suggest that steady-state is typically reached in about two to three hours after mechanical ventilation is turned on or off, estimates indicate that the average formaldehyde concentration during the occupied hours of the occupancy-based schedule may be underestimated by up to $5 \%$.

e. $T_{\text {in }}$ setpoints per the Building America protocol (Hendron and Engebrecht, 2010)

Heating setpoint $=71^{\circ} \mathrm{F}$

Cooling setpoint $=76^{\circ} \mathrm{F}$

f. No setpoint was set for indoor relative humidity

g. Based on measurements from the installed HVAC unit in the test house, the heating and cooling COPs were 2.4 and 3.5, respectively.

h. No sorption of water vapor into and out of indoor material surfaces

i. Outdoor conditions were simulated with TMY3 weather data from Knox ville-McGhee Tyson Airport (TMY Station 723260)

Table 8. Simulated weekday ventilation schedules.

\begin{tabular}{|c|c|c|c|}
\hline $\begin{array}{l}\text { Ventilation } \\
\text { Schedule }\end{array}$ & $\begin{array}{c}\text { Weekday } \\
\text { Ventilation Hours }\end{array}$ & $\begin{array}{c}\text { ASHRAE 62.2-2010 } \\
\text { Mechanical Ventilation Rates } \\
\left(\mathrm{cfm}, \mathrm{h}^{-1}\right)\end{array}$ & $\begin{array}{c}\text { ASHRAE 62.2-2013 } \\
\text { Mechanical Ventilation Rates } \\
\left(\mathrm{cfm}, \mathrm{h}^{-1}\right)\end{array}$ \\
\hline Continuous & All day & $60,0.16$ & 77 \\
\hline \multirow{2}{*}{$\begin{array}{c}\text { Intermittent } \\
\text { Occupancy-based }\end{array}$} & 8:00 am to $5: 00 \mathrm{pm}$ & 0 & 0 \\
\hline & 5:00 pm to 8:00 am & $109,0.29$ & $169,0.45$ \\
\hline \multirow{6}{*}{$\begin{array}{l}\text { Intermittent } \\
\text { Utility-based }\end{array}$} & Summer (May - Oct) & & \\
\hline & $3: 00 \mathrm{pm}$ to $8: 00 \mathrm{pm}$ & 0 & 0 \\
\hline & 8:00 pm to $3: 00 \mathrm{pm}$ & $80,0.21$ & $105,0.28$ \\
\hline & Non-summer (Nov - Apr) & & \\
\hline & 6:00 am to $11: 00 \mathrm{am}$ & 0 & 0 \\
\hline & $11: 00 \mathrm{am}$ to $6: 00 \mathrm{am}$ & $80,0.21$ & $105,0.28$ \\
\hline
\end{tabular}

a. Continuous ventilation was supplied during weekends. 
Table 9. Simulated time-of-use energy rates.

\begin{tabular}{|c|c|c|c|c|}
\hline Month & On peak hours ${ }^{a}$ & Fuel cost $(\phi / k W h)^{b}$ & On peak ( $($ /kWh) & Off peak ( $\phi / k W h)$ \\
\hline January & $3: 00$ am to $1: 00 \mathrm{pm}$ & 2.48 & 12.491 & 3.851 \\
\hline February & $3: 00$ am to $1: 00 \mathrm{pm}$ & 2.18 & 12.491 & 3.851 \\
\hline March & 3:00 am to $1: 00 \mathrm{pm}$ & 2.05 & 12.491 & 3.851 \\
\hline April & $12: 00 \mathrm{pm}$ to $10: 00 \mathrm{pm}$ & 2.23 & 12.491 & 3.851 \\
\hline May & $12: 00 \mathrm{pm}$ to $10: 00 \mathrm{pm}$ & 2.34 & 13.944 & 3.897 \\
\hline June & $12: 00 \mathrm{pm}$ to $10: 00 \mathrm{pm}$ & 2.35 & 13.944 & 3.897 \\
\hline July & $12: 00 \mathrm{pm}$ to $10: 00 \mathrm{pm}$ & 2.24 & 13.944 & 3.897 \\
\hline August & $12: 00 \mathrm{pm}$ to $10: 00 \mathrm{pm}$ & 2.23 & 13.944 & 3.897 \\
\hline September & $12: 00 \mathrm{pm}$ to $10: 00 \mathrm{pm}$ & 1.97 & 13.944 & 3.897 \\
\hline October & $12: 00 \mathrm{pm}$ to $10: 00 \mathrm{pm}$ & 2.52 & 13.944 & 3.897 \\
\hline November & $3: 00 \mathrm{am}$ to $1: 00 \mathrm{pm}$ & 2.62 & 12.491 & 3.851 \\
\hline December & $3: 00 \mathrm{am}$ to $1: 00 \mathrm{pm}$ & 2.70 & 12.491 & 3.851 \\
\hline
\end{tabular}

a. Do not apply to weekends or holidays: New Year, Memorial Day, Independence Day, Labor Day, Thanksgiving and Christmas.

b. TVA (2013).

\subsubsection{EnergyPlus Results}

We divided the EnergyPlus hourly results into three groups: 24 hours, occupied hours, and peakdemand hours. The 24-hour data provide an overall view of the results, while the occupied and peak-demand hour data supply information on periods of special interest. These data satisfy the 2010 version of ASHRAE Standard 62.2, which was the governing document when we conducted our field tests. Given that the 2013 version of Standard 62.2 was issued before this report was finished, we repeated the simulations using the new ventilation requirements listed in Table 8. We describe at the end of this section how the 2013 changes could affect energy use and indoor formaldehyde concentrations.

\subsubsection{Twenty-Four Hours}

Figures 15 through 17 summarize the 24-hour average data. Figure 15 shows that occupancybased ventilation (OV) led to higher annual HVAC loads than continuous (CV) and utility-based ventilation (UV); their respective annual HVAC loads were 66, 58 and $61 \mathrm{MBtu}$. These differences were primarily caused by higher sensible loads during the non-summer months given that the OV schedule increases mechanical ventilation when outdoor temperatures are at their lowest. Although latent loads were also higher during the summer months with the OV schedule than with the other two scenarios, the discrepancy was minimal. Figure 15 indicates that monthly average indoor relative humidity values did not exceed the comfort level of $60 \%$ per ASHRAE Standard 55-2013. However, a closer look at the simulation results from the CV and the UV schedules revealed that from May through October hourly $R H_{\text {in }}$ was higher than $60 \%$ for about $10 \%$ of the time. With the occupancy-based ventilation, the percent of the time in which $R H_{\text {in }}$ was higher than $60 \%$ was about $20 \%$. These findings indicate that a humidity controller will likely be needed in order to meet the $R H_{\text {in }}$ recommendation in a mixed-humid climate similar to that of east Tennessee. This controller will increase energy use, especially with the 
OV schedule. Note that the accuracy of the estimated indoor relative humidity values can be improved by incorporating the sorption of water vapor into and out of indoor surfaces; however, this was beyond the scope of this project.
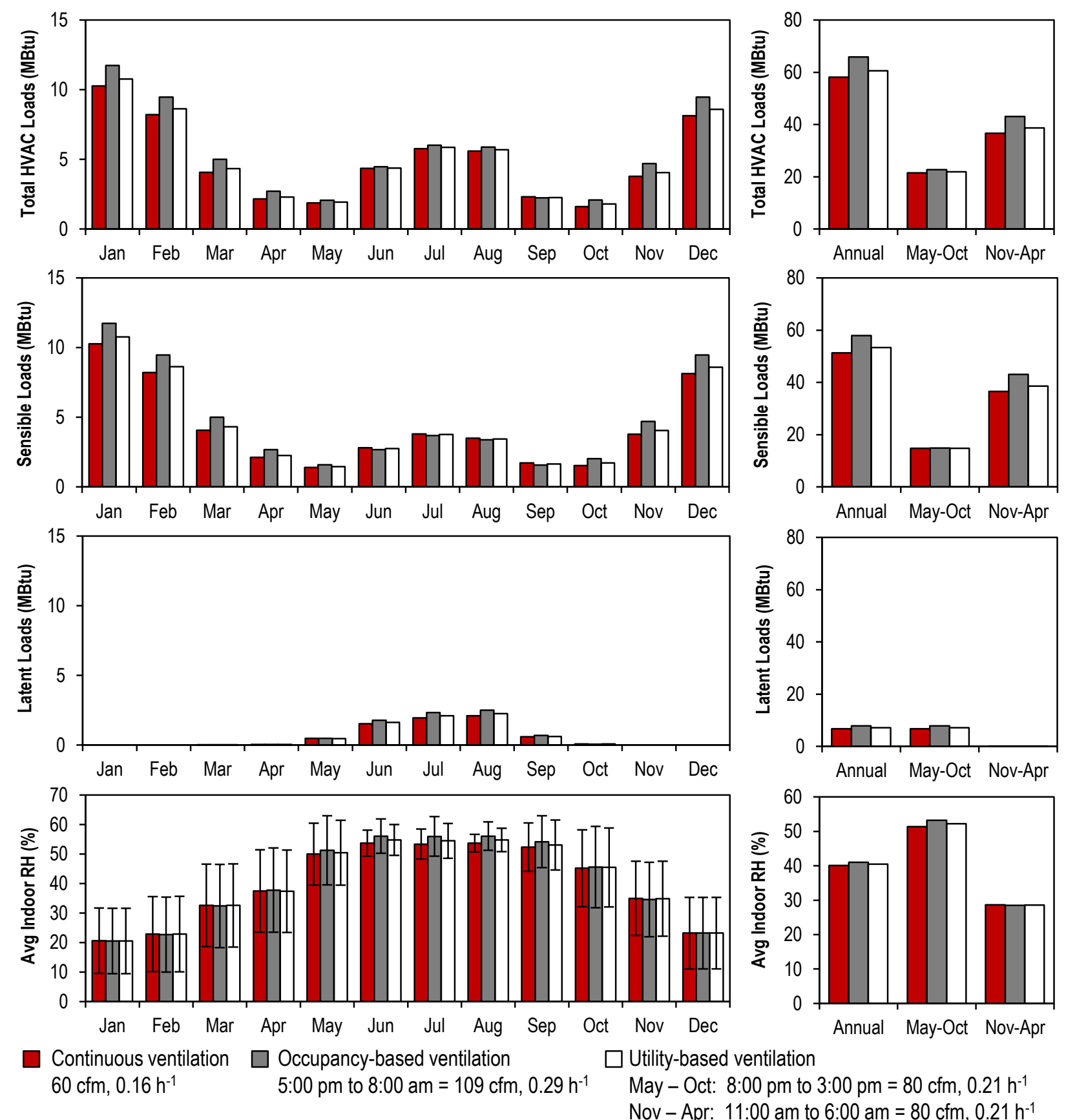

Figure 15. HVAC and indoor relative humidity estimates from 24-hour periods.

Whiskers indicate the standard deviation.

Figure 16 shows the annual electricity cost for the three scenarios we investigated. It indicates the annual costs to run the HVAC unit while providing continuous, occupancy-based, and utilitybased ventilation were $\$ 610, \$ 670$ and $\$ 620$, respectively. The evaluated mechanical ventilation 
schedules led to the monthly average formaldehyde concentrations that are illustrated in Figure 17. The standard deviation of these concentrations was highest during the spring and fall when air conditioning was not required because indoor temperatures fluctuated between the cooling and heating setpoints. OV produced monthly averages that ranged between 26 and $45 \mathrm{ppb}$, which were about $10 \%$ lower, or 3 ppb less, than what was observed with continuous ventilation. Lower formaldehyde concentrations would have been obtained with the occupancy-based schedule if occupancy hours had been considered during weekends; instead, the present model provided continuous ventilation on Saturdays and Sundays. Differences between CV and UV were minimal.

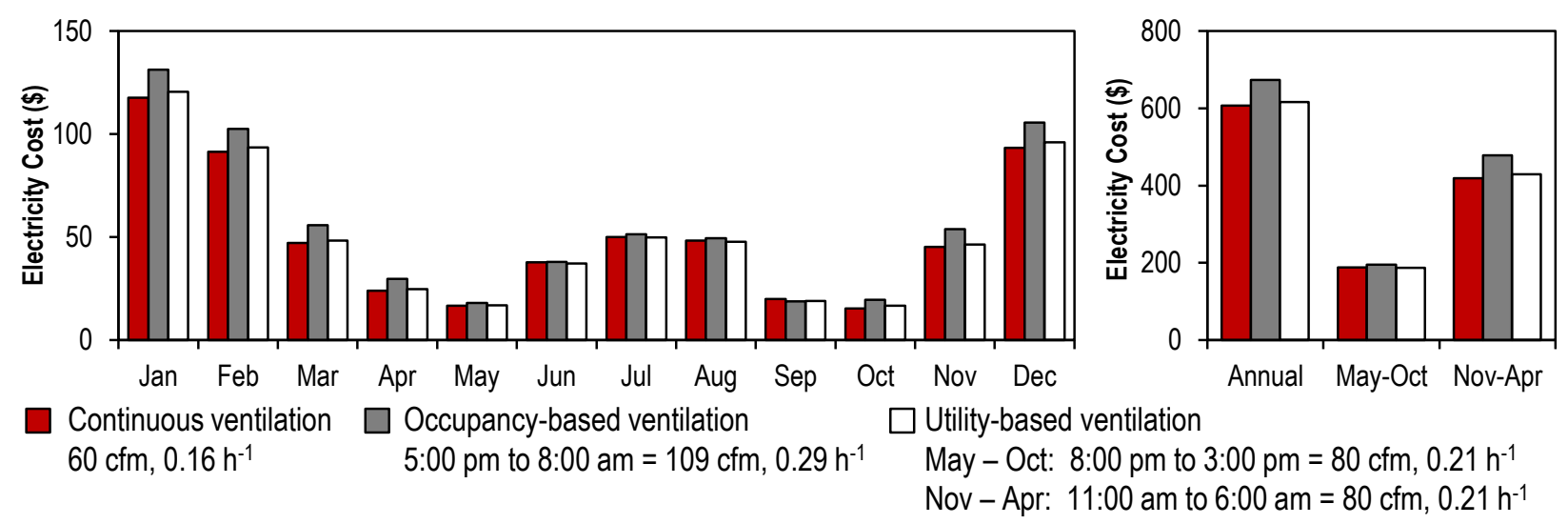

Figure 16. HVAC electricity cost estimates from 24-hour periods.

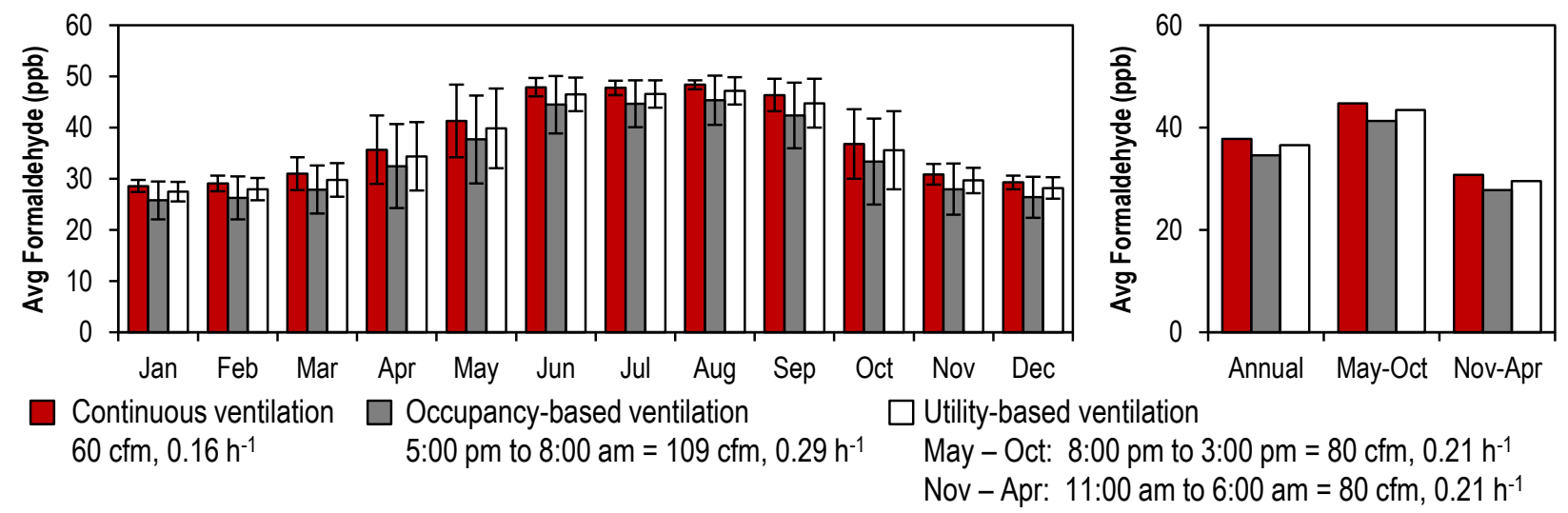

Figure 17. Formaldehyde estimates from 24-hour periods.

Whiskers indicate the standard deviation.

\subsubsection{Occupied Hours}

Figure 18 shows the monthly average formaldehyde concentrations during the occupied hours. Here, occupied hours were assumed to span from 5:00 pm to 8:00 am during weekdays, and the entire weekend. These estimates are more appropriate when evaluating human exposure to this contaminant given that exposure is calculated by multiplying concentration times the number of exposed hours. Findings indicate that with the occupied-based ventilation schedule average formaldehyde concentrations could be 10 to $20 \%$ lower, or about $6 \mathrm{ppb}$ less, than with 
continuous ventilation. As noted earlier, lower formaldehyde concentrations would have been obtained with the occupancy-based schedule by implementing a more refined weekend occupancy schedule. Differences in concentration between CV and UV were negligible; therefore, the utility-based schedule was effective in providing indoor air quality that is equivalent to that of continuous ventilation with reduced energy consumption during peak utility periods.

Formaldehyde levels were lower in the non-summer months regardless of the implemented ventilation schedule because of decreases in indoor temperature. Therefore, it is possible that mechanical ventilation rates could be reduced during this period, which could yield significant energy savings in the winter when indoor-to-outdoor temperature differentials are the highest in most of the country. However, this potential decrease in ventilation rates is dependent on reaching a consensus on acceptable indoor concentrations for formaldehyde and other pollutants.

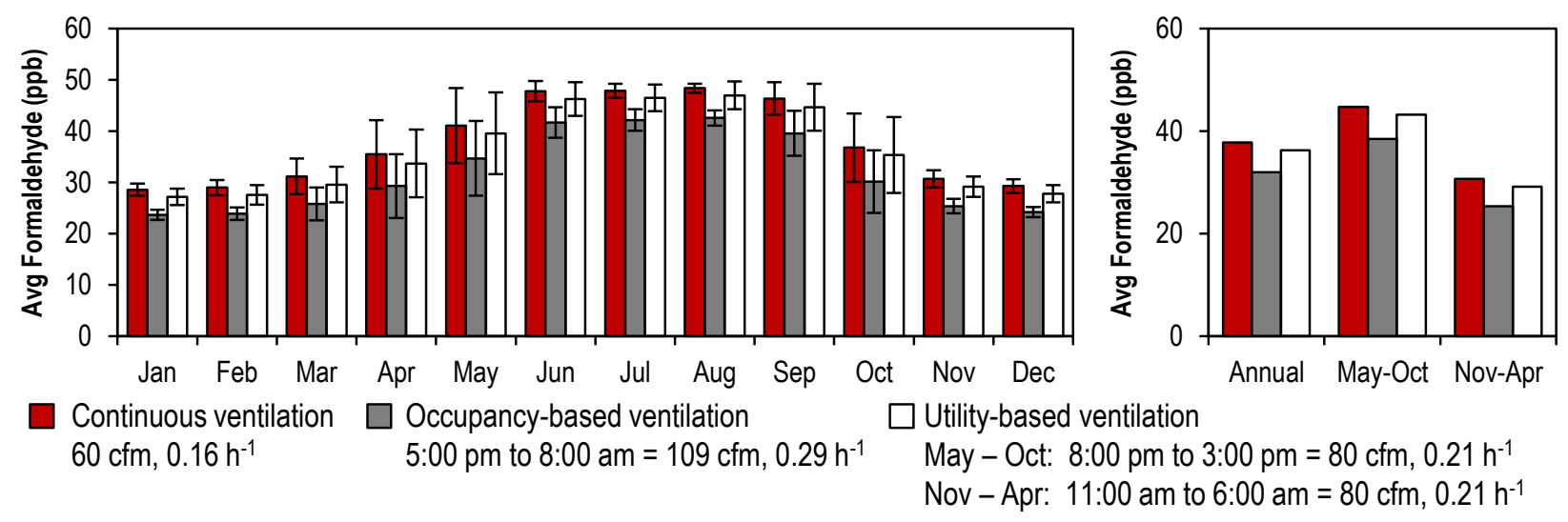

Figure 18. Formaldehyde estimates during occupied hours (weekdays: 5:00 pm to 8:00 am, weekends: whole day).

Whiskers indicate the standard deviation.

\subsubsection{Peak-Demand Hours}

HVAC loads and electricity used during peak-demand hours are summarized in Figure 19. Results suggest that, when compared to continuous ventilation, the utility-based schedule could reduce summer and non-summer HVAC loads by $0.7 \mathrm{MBtu}$ and $0.9 \mathrm{MBtu}$, respectively, during the peak-demand hours. Accordingly, electricity use could decrease by $59 \mathrm{KWh}$ and $117 \mathrm{KWh}$. If $10 \%$ of the 2.6 million households that TVA serves in Tennessee ventilated their homes using the utility-based instead of the continuous schedule, energy savings could amount to 45 million kWh per year during TVA's peak hours. 

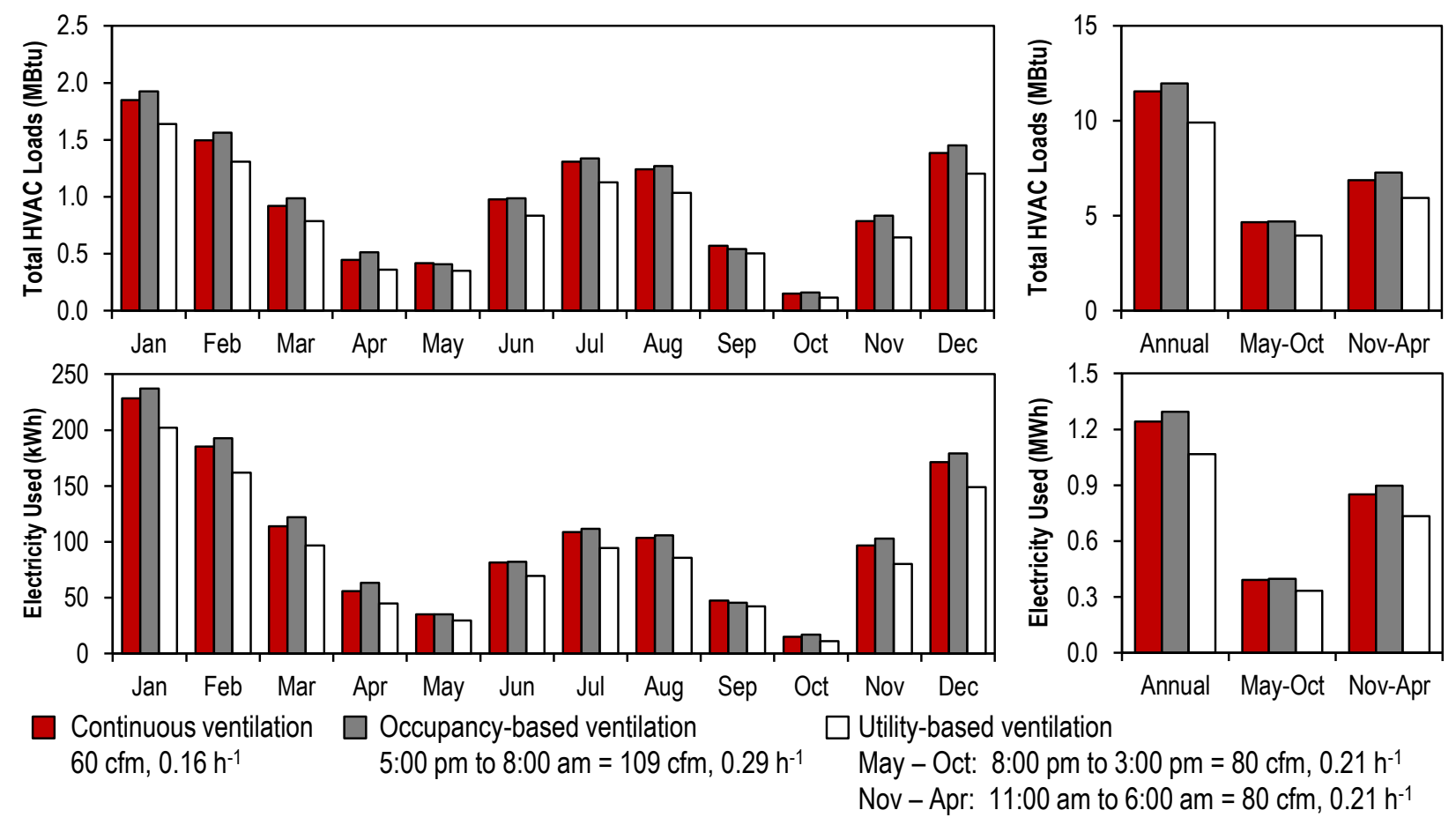

Figure 19. HVAC estimates during weekday peak-demand hours (May - Oct: 12:00 pm to 10:00 pm, Nov - Apr: 3:00 am to 1:00 pm).

\subsubsection{ASHRAE 62.2-2013}

Table 10 summarizes results from simulations where mechanical ventilation rates were based on the 2010 and the 2013 versions of ASHRAE 62.2. As indicated in Table 8, rates for the continuous and the utility-based schedules increased by about $30 \%$ in the 2013 version. This in turn could lead to an annual HVAC load and electricity cost that are about $6 \mathrm{MBtu}$ and $\$ 65$ higher, respectively. Moreover, the higher ventilation rate could translate to a decrease in annual formaldehyde of about 5 to $8 \%$, or 2 to $3 \mathrm{ppb}$. With regard to the occupancy-based schedule, 62.2-2013 specifies a ventilation rate that is 55\% greater than that from 62.2-2010. This revision could cause an annual HVAC load that is higher by $14 \mathrm{MBtu}$ and HVAC electricity cost to increase by $\$ 140$. Furthermore, the new ventilation rate could lower annual formaldehyde concentrations during occupied hours by about $8 \mathrm{ppb}$. The higher ventilation rates specified in 62.2-2013 increase the probability that a house in a mixed-humid climate will require a humidity controller in order to maintain $R H_{\text {in }}$ below $60 \%$ 
Table 10. EnergyPlus estimates for 2010 and 2013 versions of ASHRAE 62.2.

\begin{tabular}{|c|c|c|c|c|c|c|c|c|c|}
\hline \multirow{3}{*}{ Parameter } & \multicolumn{9}{|c|}{ Mechanical Ventilation Schedule } \\
\hline & \multicolumn{3}{|c|}{ Continuous } & \multicolumn{3}{|c|}{ Occupancy-based } & \multicolumn{3}{|c|}{ Utility-based } \\
\hline & 2010 & 2013 & $\%$ Change & 2010 & 2013 & $\%$ Change & 2010 & 2013 & $\%$ Change \\
\hline \multicolumn{10}{|l|}{ 24-hour data } \\
\hline \multicolumn{10}{|c|}{ Annual HVAC loads (MBtu) } \\
\hline Total & 58 & 63 & 9 & 66 & 80 & 21 & 61 & 67 & 10 \\
\hline Sensible & 51 & 55 & 8 & 58 & 70 & 21 & 53 & 59 & 11 \\
\hline Latent & 7 & 8 & 18 & 8 & 10 & 25 & 7 & 8 & 14 \\
\hline \multicolumn{10}{|c|}{ Indoor relative humidity (\%) } \\
\hline Aug avg \pm SD & $54 \pm 3$ & $55 \pm 4$ & 2 & $56 \pm 5$ & $59 \pm 6$ & 5 & $55 \pm 4$ & $57 \pm 5$ & 4 \\
\hline $90^{\text {th }}$ ptile & 58 & 60 & 3 & 62 & 65 & 5 & 60 & 63 & 5 \\
\hline \multicolumn{10}{|c|}{ HVAC Electricity cost (\$) } \\
\hline Annual & 610 & 660 & 8 & 670 & 810 & 21 & 620 & 680 & 10 \\
\hline May - Oct & 580 & 630 & 9 & 140 & 220 & 57 & 190 & 200 & 5 \\
\hline Nov - Apr & 60 & 70 & 17 & 530 & 590 & 11 & 430 & 480 & 12 \\
\hline \multicolumn{10}{|c|}{ Formaldehyde concentration (ppb) } \\
\hline Annual & $38 \pm 9$ & $36 \pm 9$ & -5 & $35 \pm 10$ & $29 \pm 11$ & -17 & $37 \pm 9$ & $34 \pm 9$ & -8 \\
\hline May - Oct & 45 & 42 & -7 & 41 & 35 & -15 & 43 & 41 & -5 \\
\hline Nov - Apr & 31 & 29 & -6 & 28 & 22 & -21 & 30 & 27 & -10 \\
\hline \multicolumn{10}{|c|}{ Occupied-hour data } \\
\hline \multicolumn{10}{|c|}{ Formaldehyde concentration (ppb) } \\
\hline Annual & $38 \pm 9$ & $36 \pm 9$ & -5 & $32 \pm 8$ & $24 \pm 8$ & -25 & $36 \pm 9$ & $33 \pm 9$ & -8 \\
\hline May - Oct & 45 & 42 & -7 & 39 & 31 & -21 & 43 & 40 & -7 \\
\hline Nov-Apr & 31 & 29 & -6 & 25 & 18 & -28 & 29 & 26 & -10 \\
\hline \multicolumn{10}{|c|}{ Peak-demand hours } \\
\hline \multicolumn{10}{|c|}{ Annual HVAC loads (MBtu) } \\
\hline Total & 12 & 13 & 8 & 12 & 14 & 17 & 10 & 10 & 0 \\
\hline
\end{tabular}

\section{Conclusions}

Intermittent ventilation can outperform continuous ventilation in homes. Field data and simulations indicate that an occupancy-based schedule could decrease exposure to formaldehyde by about $16 \%$ when compared to continuous ventilation because fresh air is introduced at strategic times. However, the occupancy-based option will also cause an increase in electricity bills in the winter because occupancy and higher ventilation rates will occur when outdoor temperatures are at their lowest. The utility-based schedule has the potential of yielding average formaldehyde concentrations during occupied hours that are equivalent to those encountered with continuous ventilation, while reducing the annual electricity use of a house by about 175 KWh during peak-demand hours. This decrease could translate to 45 million $\mathrm{kWh}$ per year 
during TVA's peak hours if $10 \%$ of the 2.6 million households it serves in Tennessee ventilated their homes using the utility-based instead of the continuous schedule.

\section{Acknowledgements}

This work was supported by the Assistant Secretary for Energy Efficiency and Renewable Energy, Office of the Building Technology Program, U.S. Department of Energy, under Contract No. DE-AC05-00OR22725. Support was also provided by the Tennessee Valley Authority.

We would like to thank Simon Pallin and Mahabir Bhandari for their input. Additionally, we would like to thank Matrix Analytical Laboratories, Inc., for their assistance with sample analysis.

\section{References}

ASHRAE. 1993. Standard 136. A method of determining air change rates in detached dwellings. Atlanta, GA: American Society of Heating, Refrigerating and Air-Conditioning Engineers.

ASHRAE. 2001, 2005, 2013. Handbook of Fundamentals. Atlanta, GA: American Society of Heating, Refrigerating and Air-Conditioning Engineers.

ASHRAE. 2010, 2013. Standard 62.2. Ventilation and acceptable indoor air quality in low-rise residential buildings. Atlanta, GA: American Society of Heating, Refrigerating and AirConditioning Engineers.

ASHRAE. 2013. Standard 55. Thermal environmental conditions for human occupancy. Atlanta, GA: American Society of Heating, Refrigerating and Air-Conditioning Engineers.

Berge A, Mellegaard B, Hanetho P, Ormstad EB. 1980. Formaldehyde release from particle board - evaluation of a mathematical model. Holz als Roh-und Werkstoff (38):251-255.

Boudreaux PR, Gehl AC, Christian JE. 2012. Occupancy simulation in three residential research houses. ASHRAE Transactions 118(Pt2):625-37.

Christian J, Gehl T, Boudreaux P, New J, Dockery R. 2010. Tennessee Valley Authority's Campbell Creek energy efficient homes project: 2010 first year performance report July 1, 2009 - August 31, 2010. Oak Ridge National Laboratory. Report ORNL/TM-2010/206.

Department of Energy (DOE). 2013. EnergyPlus engineering reference. Available: http://apps1.eere.energy.gov/buildings/energyplus/pdfs/engineeringreference.pdf

EPA (Environmental Protection Agency). 1999a. Compendium Method TO-11a: Determination of formaldehyde in ambient air using adsorbent cartridge followed by high performance liquid chromatography (HPLC). $2^{\text {nd }}$ ed. 
EPA (Environmental Protection Agency). 1999b. Compendium Method TO-17: Determination of volatile organic compounds in ambient air using active sampling onto sorbent tubes. $2^{\text {nd }}$ ed.

Hendron R, Engebrecht C. 2010. Building America house simulation protocols. National Renewable Energy Laboratory. Report TP-550-49426.

Hun DE, Siegel JA, Morandi MT, Stock TH, Corsi RL. 2009. Cancer risk disparities between Hispanic and non-Hispanic White populations: the role of exposure to indoor air pollution. Environ Health Perspect 117:1925-1931.

Hun DE, Jackson MC, Shrestha SS. 2013. Optimization of ventilation energy demands and indoor air quality in the ZEBRAlliance homes. Oak Ridge National Laboratory. Report ORNL/TM-2013/275.

IRC. 2012. 2012 International Residential Code. Country Club Hill, IL: International Code Council.

Liu X, Mason M, Guo Z, Krebs K, Roache N. 2009. Gypsum wallboard as a sink for formaldehyde. In: Proceedings from the $9^{\text {th }}$ International Healthy Buildings Conference. 13-17 September 2009, Syracuse, NY.

Logue JM, McKone TE, Sherman MH, Singer BC. 2011. Hazard assessment of chemical air contaminants measured in residences. Indoor air 21:92-109.

Matthews TG, Hawthorne AR, Thompson CV. 1987. Formaldehyde sorption and desorption characteristics of gypsum wallboard. Environ Sci Technol 21(7): 629-634.

Mortensen DK, Walker IS, Sherman MH. 2011. Optimization of occupancy based demand controlled ventilation in residences. Int J Ventilation 20:1473-2215.

Myers GE. 1984. Effect of ventilation rate and board loading on formaldehyde concentration: a critical review of the literature. Forest Prod J 34:59-68.

Myers GE. 1985. The effects of temperature and humidity on formaldehyde emission from UFbonded boards: a literature critique. Forest Prod J 35:20-31.

NIOSH (National Institute for Occupational Safety and Health). NIOSH Pocket guide to Chemical Hazards. Available: http://www.cdc.gov/niosh/npg/ [accessed 4 February 2014].

OEHAA (Office of Environmental and Health Hazard Assessment). OEHHA Acute, 8-hour and chronic reference exposure levels (REL). Available: http://oehha.ca.gov/air/allrels.html [accessed 4 February 2014].

Offermann FJ. 2009. Ventilation and indoor air quality in new homes. California Air Resources Board and California Energy Commission, PIER Energy-Related Environmental Research Program. Collaborative Report. CEC-500-2009-085. 
Rudd A, Bergey D. 2013. Ventilation system effectiveness and tested indoor air quality impacts. Building Science Corporation, RR-1309, prepared for the National Renewable Energy

Laboratory.

SKC. 2008. Operating Instructions, Sorbent Sample Tube Cat. No. 226-120, SKC Form 37356 Rev 1108.

TVA (Tennessee Valley Authority). TVA Board Meeting. Available:

http://www.tva.gov/abouttva/board/pdf/aug-22-2013_public_board.pdf.

Walker IS, Wilson DJ. 1998. Field validation of algebraic equations for stack and wind driven air infiltration calculations. Int J HVAC\&R Research 4(2):119-139.

Willem H, Hult EL, Hotchi T, Russell ML, Maddalena RL, Singer BC. 2013. Ventilation control of volatile organic compounds in new US homes: Results of a controlled field study in nine residential units. Lawrence Berkeley National Laboratory. Report LBNL-6022E. 


\section{Appendix A: VOC and Aldehyde Concentrations}

Air samples were collected in December of 2012. Concentrations for the monitored VOCs and aldehydes are presented in Tables A1 and A2.

Table A1. VOC concentrations measured in December 2012.

\begin{tabular}{lcccl}
\hline \multirow{2}{*}{ Compound } & Concentration & \multicolumn{2}{c}{ Recommended Exposure Level } & \multirow{2}{*}{ Typical Sources } \\
\cline { 2 - 4 } & $\mathrm{ppb}$ & $\mathrm{ppb}$ & Source & \\
\hline Triethylene glycol & 0.3 & - & - & Aerosol disinfectants \\
a-Pinene & 3.2 & - & - & Cleaners, fragrances, wood products \\
Camphene & 0.4 & - & - & Cleaners, fragrances, wood products \\
Limonene & 0.5 & - & - & Cleaners, fragrances, wood products \\
Acetic acid & 7.3 & 10,000 & $\mathrm{a}$ & Silicone caulks, glass cleaners \\
1,2-Dimethyl benzene & 3 & - & - & Gasoline, solvents \\
1,3,5-Trimethylbenzene & 1 & 25,000 & $\mathrm{a}$ & Gasoline, solvents \\
Methyl benzene & 5.1 & - & - & Gasoline, solvents \\
Benzene & 0.9 & 100 & $\mathrm{a}$ & Gasoline, solvents \\
Decane & 1.4 & - & - & Gasoline, solvents \\
Ethylbenzene & 1.2 & 400 & $\mathrm{~b}$ & Gasoline, solvents \\
n-Hexane & 0.6 & 50,000 & $\mathrm{a}$ & Gasoline, solvents \\
n-Octane & 1.4 & 75,000 & $\mathrm{a}$ & Gasoline, solvents \\
1,4-Dichlorobenzene & 1 & 100 & $\mathrm{~b}$ & Moth repellents, germicides \\
Styrene & 1.2 & 50,000 & $\mathrm{a}$ & Plastics, resins coatings \\
\hline
\end{tabular}

a. Time-weighted average (TWA) concentration for up to a 10-hour workday during a 40-hour workweek specified by the National Institute for Occupational Safety and Health (NIOSH)

b. Chronic exposure level from the California Office of Environmental and Health Hazard Assessment (OEHHA).

Table A2. Aldehyde concentrations measured in December 2012.

\begin{tabular}{lcccc}
\hline Compound & $\begin{array}{c}\text { Concentration } \\
\mathrm{ppb}\end{array}$ & $\begin{array}{c}\text { Recommended Exposure Level } \\
\text { Spb }\end{array}$ & Source & Typical Sources \\
\hline Formaldehyde & 38 & $16,7.4$ & $\mathrm{a}, \mathrm{b}$ & Compressed wood, adhesives, car exhaust \\
Acetaldehyde & 6 & 78 & $\mathrm{~b}$ & Paints, tobacco smoke, car exhaust \\
\hline
\end{tabular}
a. Time-weighted average (TWA) concentration for up to a 10-hour workday during a 40-hour workweek specified by the National Institute for Occupational Safety and Health (NIOSH)
b. Chronic exposure level from the California Office of Environmental and Health Hazard Assessment (OEHHA). 